\title{
Temporal trends in age and size at maturation of four North Sea gadid species: cod, haddock, whiting and Norway pout
}

\author{
Lise Marty $^{1,4, *}$, Marie-Joëlle Rochet ${ }^{2}$, Bruno Ernande ${ }^{1,3}$ \\ ${ }^{1}$ IFREMER, Laboratoire Ressources Halieutiques, 150 Quai Gambetta, BP 699, 62321 Boulogne-sur-mer, France \\ ${ }^{2}$ IFREMER, Ecologie et Modèle pour l'Halieutique, rue de l'Ile d'Yeu, BP 21105, 44311 Nantes Cedex 03, France \\ ${ }^{3}$ IIASA, Evolution and Ecology Program, Schlossplatz 1, 2361 Laxenburg, Austria \\ ${ }^{4}$ Present address: Center for Ocean Life, National Institute of Aquatic Resources (DTU-Aqua), Technical University of \\ Denmark, Jægersborg Allé 1, 2920 Charlottenlund, Denmark
}

\begin{abstract}
Younger ages and smaller sizes at maturation have been observed in commercial fish stocks over the last century. We establish that age and length at $50 \%$ proportion mature (i.e. the proportion of mature individuals in a population or the probability that an individual is mature) decreased from the 1970s to the 2000s in North Sea cod Gadus morhua, haddock Melanogrammus aeglefinus and whiting Merlangius merlangus, but not in Norway pout Trisopterus esmarkii. The potential contributions of demography, phenotypic plasticity and evolution to these trends were assessed. First, maturation trends were extricated from demographic effects and growth-dependent plasticity by estimating probabilistic maturation reaction norms (PMRNs). PMRN midpoints have significantly shifted downwards at most ages for cod, haddock and whiting, but not for Norway pout. Second, increased temperature and food abundance, loosened trophic competition and relaxed social pressure may also trigger growth-independent plasticity in maturation. Principal component regression of PMRN midpoints on annual estimates of relevant environmental variables exhibiting a temporal trend suggest that, despite some evidence of environmental effects, PMRN trends were mostly independent of growth-independent plasticity in haddock, whiting and male cod, but not in female cod. According to these findings, evolution of maturation, potentially in response to fishing, is plausible in haddock, whiting and male cod, but unlikely for Norway pout, and does not explain trends in female cod maturation. In agreement with life-history theory, the maturation response was larger in fast-growing, late- and large-maturing species exhibiting moderate reproductive effort.
\end{abstract}

KEY WORDS: Probabilistic maturation reaction norm - Demography - Phenotypic plasticity · Fisheries-induced evolution $\cdot$ Life-history strategy $\cdot$ Maturity $\cdot$ Growth $\cdot$ Reproductive investment

\section{INTRODUCTION}

Trends towards younger ages and smaller sizes at maturation have been observed in commercial fish stocks over the last century (reviewed by Jørgensen et al. 2007, Sharpe \& Hendry 2009, Audzijonyte et al. 2013). Maturing young and small implies smaller adult size because growth rate decreases markedly after maturation owing to the trade-off between growth and reproduction (Stearns 1992). Consequently, fecundity is lowered due to size-dependence, and offspring survival may decrease due to parental age and body-size effects on the size and quality of eggs and larvae (Trippel 1995, Berkeley et al. 2004), which is counterbalanced by increasing survival until reproduction. Due to the effect of individual size on 
reproduction, maturing younger and at a smaller size may be detrimental to population biomass and reproductive capacity, which in turn may reduce fishing yields (Law \& Grey 1989, Heino 1998) and hamper population biomass rebuilding after collapse (Hutchings 2005, Enberg et al. 2009). Life-history traits could therefore serve as indices of the state of a population for management (Rochet 2000a), or early warning signals before stock collapse (Olsen et al. 2004).

Maturity ogives describe the proportion of mature individuals in a population (or the probability that an individual is mature) as a function of age and/or size. The age and size at $50 \%$ proportion mature, traditionally called $A_{50}$ and $L_{50}$, are common indicators of age and size at maturity (Trippel 1995), and trends in maturity in exploited fish populations are primarily assessed through $A_{50}$ and $L_{50}$. The proportion mature at a given age and size depends on maturation tendency according to age and size, but also on survival and growth until the focal age and size. Therefore, 3 main mechanisms can induce temporal changes in $A_{50}$ and $L_{50}$ : demography, phenotypic plasticity and evolution (Fig. 1).

The demographic mechanism influences maturity ogives whenever fishing induces a change in the maturity structure of the population. With size-selective fishing, the larger an individual within any age-class, the more likely it is to be mature but also the more vulnerable it is to fishing, which tends to reduce the proportion mature at any age, and increase $A_{50}$. Fishing may also be selective according to maturity status, targeting preferentially adults on the spawning grounds, which should increase $A_{50}$, or juveniles on the feeding grounds, which should decrease $A_{50}$, during the reproductive season. In short, the demographic mechanism induces changes in $A_{50}$ and $L_{50}$, the direction of which depends on the fishing pattern.

The second mechanism involves phenotypic plasticity of age and size at maturation. In particular, age

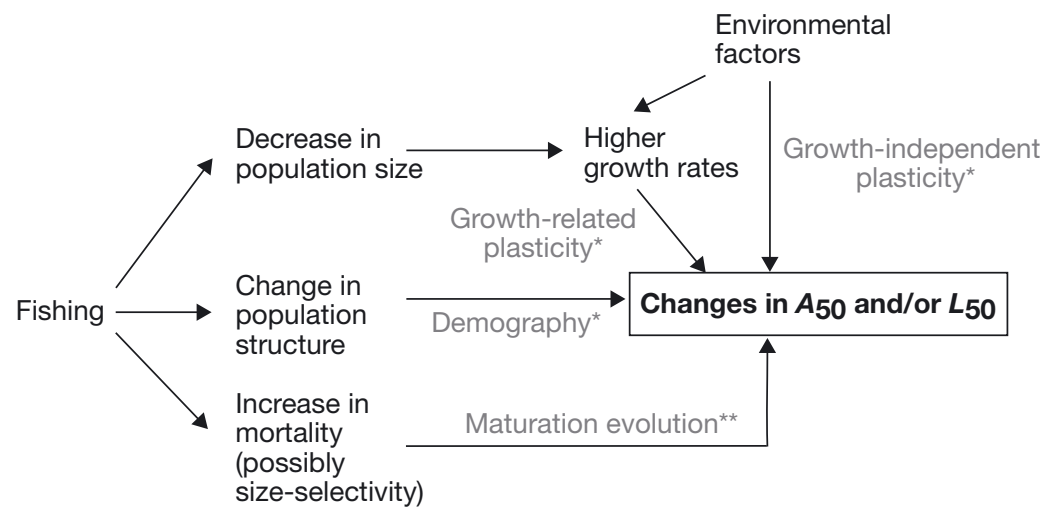

Fig. 1. Mechanisms potentially involved in maturation trends in exploited populations. * within-generation mechanism, ${ }^{* *}$ between-generation mechanism and size at maturation are strongly influenced by somatic growth rate, which largely depends on environmental conditions such as food resources or temperature (Weatherley 1990); variations in growth may also be partly genetic (Kinnison et al. 2011). In harvested fish populations, earlier maturation can result from the relaxation of trophic competition due to reduction in population size, which accelerates growth (Reznick 1993, Trippel 1995). Furthermore, some environmental factors may induce maturation plasticity directly, i.e. without influencing growth. Body condition correlates positively with maturation propensity (Marteinsdottir \& Begg 2002, Grift et al. 2007, Mollet et al. 2007, Uusi-Heikkilä et al. 2011): ecological factors enhancing body condition, such as food abundance (Siems \& Sikes 1998), can therefore trigger trends in maturity ogives. Likewise, elevated temperature accelerates maturation (Dhillon \& Fox 2004, Morita et al. 2009). In some fish species, maturation is also influenced by the social and/or size structure of the population (Hutchings et al. 1999) that fishing may alter by reducing the population's abundance or truncating its age and size structure: the resulting relaxation of the social pressure exerted by old and/or large dominant individuals may enable younger and smaller ones to mature (Sohn 1977, Hobbs et al. 2004, Kraak 2007).

As a third mechanism, maturation propensity per se may evolve in response to fishing-induced selection. Uniformly elevated mortality favours earlier maturation, which balances the decrease in survival by an increase in lifelong fecundity (Stearns 1992, Charlesworth 1994, Ernande et al. 2004, Gårdmark \& Dieckmann 2006), and the selective pressure against large- and late-maturing individuals is strengthened when fishing is size-selective. Theoretical predictions suggest that species with late maturation and large adult size should be more prone to evolutionary changes in age and size at maturation in response to fishing, because of higher cumulated mortality before maturation (Heino \& Godø 2002). Moreover, species with fast growth rate, weak reproductive investment and low natural mortality should be particularly sensitive to harvest-induced evolutionary changes (Ernande et al. 2004).

Understanding which processes underlie maturity changes in wild populations therefore requires disentangling the influence of demographic, environmental and genetic factors. 
Phenotypic plasticity of age and size at maturation in response to somatic growth variation can be described using the concept of the maturation reaction norm, defined as the combination of age and size at maturation that is expressed by a given genotype for different growth rates (Stearns \& Crandall 1984, Stearns \& Koella 1986). The probabilistic maturation reaction norm (PMRN) extends this deterministic concept to a probabilistic framework (Heino et al. 2002a) and describes the probability that an individual becomes mature according to age and size. This probability is conditional on the individual being immature and having reached the point defined by the focal age and size, which requires surviving and following a growth trajectory until this point. Consequently, by definition, PMRNs estimate maturation probability independent of the influence of survival and growth, whatever the source of variation in the latter (natural or anthropogenic, and genetic or plastic, respectively; Dieckmann \& Heino 2007). Using PMRNs, changes in maturation propensity independent of demography and growth-dependent plasticity have been detected in many fish stocks (reviewed by Dieckmann \& Heino 2007). However, the method cannot distinguish evolutionary changes from growthindependent plasticity due to environmental factors influencing maturation other than via growth; unless these factors are included as additional explanatory variables, they can drive plastic variations in PMRNs (Kraak 2007, Marshall \& McAdam 2007, UusiHeikkilä et al. 2011).

The North Sea has been extensively exploited for centuries, with cod and haddock being major targets. Gadid stocks have been shown to be prone to fisheries-induced changes in their life history (Jørgensen 1990, Olsen et al. 2004, Pardoe et al. 2009, Vainikka et al. 2009, Devine \& Heino 2011, Wright et al. 2011a). North Sea gadids therefore provide an adequate study system for a comparative analysis of fisheries-induced changes in maturation. In this study, we analysed 20 to $30 \mathrm{yr}$ time series of maturity data in 4 North Sea gadid species: cod Gadus morhua, haddock Melanogrammus aeglefinus, whiting Merlangius merlangus and Norway pout Trisopterus esmarkii. Earlier studies found shifts towards lower $A_{50}$ and $L_{50}$ in North Sea cod and haddock stocks from 1983 to 1995 (Rochet 2000b) and in North Sea Norway pout from 1983 to 2006 (Lambert et al. 2009). PMRN shifts have also been observed in similar direction for inshore haddock along the Scottish coast between the mid-1970s and the mid-1990s (Wright et al. 2011a) and for 3 subpopulations of North Sea cod (Wright et al. 2011b).
We start by analysing temporal trends in North Sea gadids' maturity ogives and then aim to disentangle the mechanisms responsible for these. To this end, we estimated time series of PMRNs in order to remove demographic and growth-dependent plasticity influences and time series of juvenile length-at-age to assess the potential role of growth rates. We further examined the effects of environmental variables that could influence maturation through growthindependent phenotypic plasticity, namely (1) summer water temperature, (2) food abundance, using the recruitment indices of sandeel Ammodytes marinus and Norway pout that are important prey of cod, haddock and whiting (Hislop 1997) and (3) competition for trophic resources and social structure, represented by recruitment indices of the 4 gadid species. Finally, since the 4 stocks belong to the same family and the same area, but have different life histories, we assessed whether the observed shifts in North Sea gadid PMRNs are in agreement with theoretical predictions about the influence of life-history strategy on the magnitude of evolutionary changes in maturation propensity due to fishing.

\section{MATERIALS AND METHODS}

\section{North Sea gadids}

Gadids form a family of marine fish species that are distributed in temperate to cold waters and show mainly bentho-demersal behaviour. Several gadids are of commercial importance, including our 4 model species. North Sea cod is widely distributed throughout the North Sea and is structured in many sub-populations (Hutchinson et al. 2001, Wright et al. 2006, Nielsen et al. 2009, Wright et al. 2011b). North Sea haddock usually occurs north of the Dogger Bank (a sandbank located at $54.5^{\circ} \mathrm{N}$ ), with major spawning areas in the northern North Sea and off the Scottish east coast, possibly corresponding to 2 different subpopulations (Wright et al. 2011a). Adult whiting are widespread in the North Sea, whereas juveniles concentrate off the Scottish coast, in the south-eastern bight of the North Sea, and along the coast of the Netherlands. Three genetically distinct whiting subpopulations have been identified (Charrier et al. 2007). The distribution area of North Sea Norway pout is given as the northern North Sea $\left(>57^{\circ} \mathrm{N}\right)$, at depths between 50 and $200 \mathrm{~m}$ (Sparholt et al. 2002).

All 4 stocks have high fecundity, spawn in winter and/or spring and have pelagic eggs and larvae (Hislop 1984), but they exhibit different growth and mat- 
uration strategies: in the 1970 s, cod reached maturity between 3 and $5 \mathrm{yr}$ old at the largest size, i.e. between 50 and $70 \mathrm{~cm}$, haddock between 3 and $4 \mathrm{yr}$ old at a size between 30 and $40 \mathrm{~cm}$ and whiting around 2 yr old between 20 and $25 \mathrm{~cm}$. In the 1980s, Norway pout reached maturity between 1 and $2 \mathrm{yr}$ old at a size between 10 and $15 \mathrm{~cm}$. Cod, haddock and whiting are long-lived species whose maximum lifespan reaches roughly $20 \mathrm{yr}$, whereas Norway pout usually die before age 5 .

\section{Data}

\section{Biological data}

Biological data were collected during the North Sea International Bottom Trawl Survey (NS-IBTS; ICES 2010), which covers the North Sea, Skagerrak and Kattegat in order to provide recruitment indices of herring, cod, whiting, haddock, Norway pout, mackerel, sprat and saithe. The NS-IBTS has been conducted by 8 countries during the first quarter of each year since 1965 (as of more recently, the third quarter is also covered, but those data were not used in this study). The survey area is divided in statistical rectangles of $1^{\circ}$ longitude $\times 0.5^{\circ}$ latitude in which 1 to 6 hauls are towed using a Grande Ouverture Verticale trawl at a recommended ground speed of 4 knots. All fished species are sorted and numbered for further processing (ICES 2012). Individuals' total length is measured to the nearest $\mathrm{cm}$ or half-cm (depending on species), and their sex and maturity stage are determined by direct observation of gonads. Fish otoliths are sampled for aging using standard reading of growth rings. Otolith sampling is stratified into 9 RoundFish Areas (RFAs), with RFA 1 to 7 covering the North Sea and RFA 8 and 9 covering the Skagerrak-Kattegat, and according to length within each RFA. Age is then determined for 8 to 16 individuals (depending on species) per length class $(1 \mathrm{~cm}$ width for all species) in each RFA.

Resulting sex-maturity-age-length keys (SMALKs) were extracted from the online database of trawl surveys (DATRAS, www.ices.dk/marine-data/dataportals/Pages/DATRAS.aspx) maintained by the International Council for the Exploration of the Sea (ICES), over the period 1974 to 2012 for cod, haddock and whiting, and 1983 to 2012 for Norway pout. We used data from the first quarter only (when gonads are ripe because individuals are prepared to or start spawning) to avoid confusion between spent gonads (empty gonads that have shrunken after spawning) and immature ones. Catch per unit effort by length class (in number per trawl-hour) was used to estimate abundance indices per year, RFA and length class for the 4 stocks, assuming a constant trawl width and using RFA surfaces for the elevation. These indices were used to weigh individual data from SMALKs, in order to investigate average maturity and length-atage at the scale of the entire North Sea for each stock, while eliminating the potential bias resulting from the spatial and length stratification of sampling and accounting for potential variations in growth and maturity between RFAs.

Skagerrak and Kattegat were excluded because sampling started later than in other areas. While cod, haddock and whiting were observed in all areas during the period considered, Norway pout was absent from areas 5 and 6 . Ages 1 to 6 were used for cod, haddock and whiting, and 1 to 3 for Norway pout. Resulting sample sizes were: 27784 female cod, 28656 male cod, 46909 female haddock, 46193 male haddock, 54369 female whiting, 47282 male whiting, 9026 female Norway pout and 6519 male Norway pout.

\section{Environmental factors}

Environmental factors potentially affecting maturation via growth-independent plasticity were collected from different sources. Sea surface temperatures were extracted from the online OCEAN database (ocean. ices.dk/data/surface/surface.htm) maintained by ICES. As annual temperature variations were strongly correlated between the central area (Marsden subsquare $216 ; 3,55-60^{\circ} \mathrm{N}, 0-5^{\circ} \mathrm{E}$ ) and adjacent areas (mean correlation of 0.74 with Marsden subsquares $216 ; 1,181 ; 3$, $216 ; 4,252 ; 1,217 ; 1,216 ; 1$, maximum 0.92, minimum 0.55), we selected data from the central area and left out stations at which depth was less than $20 \mathrm{~m}$. We averaged the data monthly from June to August and then annually to obtain mean summer sea surface temperature. We focused on summer, as this is when vitellogenesis takes place (Kjesbu \& Witthames 2007) and thus the maturation process starts. Summer sea surface temperature was strongly correlated (correlation of 0.8 ) to summer sea bottom temperature. Variations in sea surface temperature were thus considered as indicative of variations in temperature for the whole water column during the summer period despite stratification. Missing data for a given month (August 1973, June 1982, June 1985 and August 1986) were replaced by average temperature in the same month over the 2 preceding and following years (mean number of data per month: 470.7). Indices of food abundance, repre- 
sented by sandeel and Norway pout recruitment indices, and indices of intra-specific competition and social structure, represented for each stock by its own recruitment indices at age 0 or 1, were estimated by the ICES Working Group on North Sea Skaggerak and Kattegat using virtual population analyses. Recruitment estimates were available over the period 1974 to 2011 for cod and haddock, 1983 to 2011 for sandeel and Norway pout and 1990 to 2011 for whiting (ICES 2012).

\section{Age and length at maturity}

All statistical analyses were conducted separately for each species and sex. Maturity ogives $o$ were estimated using logistic regression with a logit link function. The logit of the probability $o_{i}$ of individual $i$ of being mature was modelled as a function of its cohort $c$ as a factor and (1) its age $a_{i}$ as a continuous variable

$$
\operatorname{logit}\left(o_{i}\right)=\alpha_{0, c_{i}}+\alpha_{1, c_{i}} a_{i}
$$

(2) its length $l_{i}$ as a continuous variable

$$
\operatorname{logit}\left(o_{i}\right)=\alpha_{0, c_{i}}+\alpha_{1, c_{i}} l_{i}
$$

or (3) both, with an interaction

$$
\operatorname{logit}\left(o_{i}\right)=\alpha_{0, c_{i}}+\alpha_{1, c_{i}} a_{i}+\alpha_{2, c_{i}} l_{i}+\alpha_{3, c_{i}} a_{i} l_{i}
$$

Models (1) and (2) were respectively used to compute the age $A_{50}$ and length $L_{50}$ at which the probability of being mature reaches $50 \%$, while model (3) was used for PMRN estimation (see below). Regardless of short-term variation, these annual estimates were used to investigate global temporal trends in age and length at maturity over the whole time period by means of linear regression. Predicted $A_{50}$ and $L_{50}$ were regressed linearly against cohort $C$ as a continuous variable, weighted by the inverse of the standard error of each estimate,

$$
\begin{aligned}
& A_{50, c}=\alpha_{0}+\alpha_{1} c+\varepsilon_{c} \\
& L_{50, c}=\alpha_{0}+\alpha_{1} c+\varepsilon_{c}
\end{aligned}
$$

where $\varepsilon$ here and in the following models is a normally distributed error term, and its subscript stands for the data point resolution, here 1 per cohort $C$.

\section{Length-at-age}

To compute maturation reaction norms (see below), the length-at-age $l_{i}$ of individual $i$ was estimated as a linear function of its cohort $c_{i}$ and age $a_{i}$ as factors

$$
l_{i}=\alpha_{0, a_{i}}+\alpha_{1, c_{i}}+\alpha_{2, a_{i} \times c_{i}}+\varepsilon_{i}
$$

To analyse temporal trends in juvenile length-atage, individual length $l_{i}$ was linearly regressed against age $a_{i}$ as a factor and cohort $C_{i}$ as a continuous variable, for ages 1 to 3 for cod, haddock and whiting, and for ages 1 and 2 for Norway pout

$$
l_{i}=\alpha_{0, a_{i}}+\alpha_{1, a_{i}} c_{i}+\varepsilon_{i}
$$

\section{PMRNs}

Estimation method

Since for our model species first-time and repeat spawners cannot be distinguished, PMRNs were estimated by the demographic method (Barot et al. 2004). The probability of maturing is given by

$$
m(c, a, l)=\frac{o(c, a, l)-o(c, a-1, l-\Delta l)}{1-o(c, a-1, l-\Delta l)}
$$

with $o, C, a$ and $l$ as in model (3), and $\Delta l$ the agespecific annual growth increment computed as $\Delta l(c, a)$ $=l(c, a)-l(c, a-1)$ using model (5). The probability of maturing at age $a$ and length $l$ is thus obtained as the ratio between the fraction of individuals which matured between age $a-1$ and $a$, accounting for growth in length $\Delta l$ between the 2 ages, and the proportion of immature individuals at age $\mathrm{a}-1$, to achieve a probability conditional on being immature (Barot et al. 2004).

This method assumes that mature and immature individuals have the same growth and survival rates within an age class and cohort. Barot et al. (2004) showed that the method is robust to violations of these simplifying assumptions when sample size is larger than 100 individuals per age class and cohort and when age is treated as a factor. Because sample sizes were low, age was treated as a continuous variable, which allows more robust estimation of PMRNs with small sample sizes, but implies the assumption that maturing probability varies linearly with age. PMRNs could be estimated for each cohort for cod, haddock and whiting, whereas for Norway pout, 3-cohort pools were necessary to obtain sufficient sample sizes.

Temporal trends in maturation propensity

To analyse temporal trends in maturation propensity, we used PMRN midpoints, i.e. the length $L_{\mathrm{p} 50, a}$ at which the probability of maturing is $50 \%$ at age $a$, determined by linear interpolation (Barot et al. 2004). Since PMRNs are obtained by combining several statistical analyses, confidence intervals are estimated 
by bootstrapping (Manly 1997, Barot et al. 2004). Individuals in the original data set were resampled 1000 times with replacement while respecting sample size and the stratification by cohort, RFA and length class. Confidence intervals were estimated as the $95 \%$ percentiles of the bootstrapped midpoint distribution.

Temporal trends in PMRN midpoints were tested by linear regression of $L_{\mathrm{p} 50, a, c}$ against age $a$ as a factor and cohort $C$ as a continuous variable, taking into account ages 1 to 4 for cod, ages 1 to 3 for haddock and whiting and ages 1 and 2 for Norway pout, weighted by the inverse of the bootstrap standard deviation of each midpoint to lower the influence of imprecise estimates on the regression

$$
L_{\mathrm{p} 50, a, c}=\alpha_{0, a}+\alpha_{1, a} c+\varepsilon_{a, c}
$$

\section{Effects of environmental factors on maturation propensity}

Growth-independent plasticity of maturation propensity in response to environmental variables was analysed through the effects on PMRN midpoints of summer water temperature (as an indicator of environmental fluctuations), sandeel and Norway pout recruitment indices (as indicators of food abundance) and the recruitment indices of each species, at age 0 for haddock and age 1 for cod and whiting (as indicators of social structure or intra-specific competition depending on cohort ages, see below).

Although short-term fluctuations in environmental factors may induce short-term variations in maturation, we were interested in long-term trends in maturation. Therefore, only environmental factors exhibiting a significant temporal trend, as assessed by linear regression against year, were selected for analysis.

PMRN midpoints $L_{\mathrm{p} 50, a}$ at age a were regressed against annual estimates of the selected environmental factors $e_{j, c+a-\Delta}$ and cohort $c$ as continuous variables,

$$
L_{\mathrm{p} 50, a, c}=\alpha_{0}+\alpha_{1} c+\sum_{j} \sum_{\Delta=1}^{a} \alpha_{j, a-\Delta} e_{j, c+a-\Delta}+\varepsilon_{c}
$$

where $j$ denotes the environmental factor considered and $c+a-\Delta$ the year of the estimate with a time lag $\Delta$ varying from 1 to a yr. We thus estimated the effect of each environmental factor in each year from the birth of the cohort (age 0 ) until age $a-1$. Recruitment of the cohort itself $(\Delta=a$, age $=0)$ is meant to account for trophic competition experienced by this cohort at any age because it was strongly correlated with cohort abundance at other ages (1 to $a-1)$. Recruitment of other cohorts of the species when the focal cohort $c$ is older $(\Delta<a$, age $>0)$ are included to represent social structure. A more natural indicator of the latter would have been spawning stock biomass, but it was strongly correlated with recruitment, which was included in the model for $\Delta=a$, and we therefore used recruitment at $\Delta<a$ as an indirect indicator of social structure. For temperature and prey recruitment indices, the time lag $\Delta$ allows determining at which ages the maturation process is critically affected by climate fluctuations and food abundance.

Because of their temporal trends, the explanatory variables were strongly correlated. To overcome any potential bias in the estimated effects via linear regression due to collinear explanatory variables, coefficients of model (9) were estimated using principal component regression (PCR), a method that estimates regression coefficients on principal components. Principal component analysis uses orthogonal transformation to convert a set of correlated variables into a set of uncorrelated ones, called principal components. $L_{\mathrm{p} 50}$ estimates were then regressed against the principal components of explanatory variables in model (9), and the resulting PCR coefficients were transformed back to the original coordinate axes to obtain unbiased regression coefficients, standard errors and p-values associated with each explanatory variable (Coxe 1986, Fekedulegn et al. 2002). The family-wise Type I error rate was constrained to a probability of $\alpha=0.05$ for each species by adjusting p-values according to the Holm-Bonferroni method (Holm 1979). We used all principal components for the PCR. For each environmental variable with a significant effect on $L_{\mathrm{p} 50}$, we further calculated the amount of change ascribable to this effect as the product of the regression coefficient of the environmental variable according to time, the regression coefficient of $L_{\mathrm{p} 50}$ according to the environmental variable in the PCR and the duration of the time period.

These analyses were applied to the age at which $L_{\mathrm{p} 50}$ was best estimated and weighted by the inverse of each $L_{\mathrm{p} 50}$ estimate bootstrap standard deviation for male and female cod, haddock and whiting. For Norway pout, this analysis was precluded by the limited amount of $L_{\mathrm{p} 50}$ estimates.

\section{Effect of life-history parameters on the magnitude of maturation change}

To examine whether the observed changes in North Sea gadid PMRNs were in agreement with theoretical predictions about the influence of life-history strategy on the magnitude of the evolutionary response of 
maturation to fishing, we estimated several additional life-history parameters. To estimate juvenile growth rate and reproductive investment, we considered a 2-stage growth model in which individual growth is linear with age before maturation and declines afterwards to converge to an asymptotic length due to the trade-off between growth and reproduction (Kozłowski \& Wiegert 1986, 1987, Kozłowski 1992). The model is given by

$$
\begin{cases}l(a)=l_{0}+g a & \text { for } 1 \leq a \leq a_{\mathrm{m}} \\ l(a)=l\left(a_{\mathrm{m}}\right)+\frac{g}{u}\left\{1-\exp \left[-u\left(a-a_{\mathrm{m}}\right)\right]\right\} & \text { for } a>a_{\mathrm{m}}\end{cases}
$$

with $l_{0}$ : length at age $0, g$ : juvenile growth rate, $a_{\mathrm{m}}$ : age at maturation and $u$ : reproductive effort. $a_{\mathrm{m}}$ was estimated as the mean maturation age from age-based maturity ogives: $o(a)$ being the proportion of mature individuals at age a in the population, we estimated the proportion of individuals becoming mature at each age as $o(a)-$ $o(a-1)$, the mean age at maturation was then estimated as a weighted mean of age using the proportion of maturing individuals at each age as weights. $l_{0}, g$ and $u$ were estimated by nonlinear least square fitting of model (10) to individual data on length, age and maturity status. Model (10) was fitted for each species and each sex separately, using data of cohorts 1974 to 1979 pooled for cod, haddock and whiting, and cohorts 1983 to 1986 for Norway pout. We focused on the earlier cohorts because the aim was to assess the influence of the original life-history trait values on subsequent changes in maturation. Mean maturation size $l_{\mathrm{m}}$ was estimated as the product of $a_{\mathrm{m}}$ and $g$. We then contrasted relative changes $\delta L_{\mathrm{p} 50}$ in PMRN midpoints across species together with $g, u, a_{\mathrm{m}}$ and $l_{\mathrm{m}}$, using Spearman correlation. Relative changes $\delta L_{\mathrm{p} 50}$ were computed as $\delta L_{\mathrm{p} 50}=\left(L_{\mathrm{p} 50}\left(C_{\mathrm{f}}\right)-L_{\mathrm{p} 50}\left(C_{\mathrm{i}}\right)\right)$ $/ L_{\mathrm{p} 50}\left(C_{\mathrm{i}}\right)$, where $C_{\mathrm{i}}$ is the initial and $C_{\mathrm{f}}$ the final cohort. We used the total change in $L_{\mathrm{p} 50}$ instead of only the cohort contribution

Fig. 2. Times series of age $\left(A_{50}\right.$, black squares $)$ and length ( $L_{50}$, grey circles) at $50 \%$ maturity for $(\mathrm{A}, \mathrm{C}, \mathrm{E}, \mathrm{G})$ male and $(\mathrm{B}, \mathrm{D}, \mathrm{F}, \mathrm{H})$ female $(\mathrm{A}, \mathrm{B})$ cod, $(C, D)$ haddock, $(E, F)$ whiting, and $(G, H)$ Norway pout. Vertical bars give the $95 \%$ confidence interval. Dashed lines give the regression line against cohort whenever significant at the $5 \% \alpha$-risk level estimated in PCR analyses because (1) environmental contributions were weak (see 'Results'), and (2) we wanted to include Norway pout for which no PCR analyses could be performed. All analyses were performed using R (R Development Core Team 2013).

\section{RESULTS}

\section{Temporal trends in age and length at maturity}

Age $A_{50}$ and length $L_{50}$ at $50 \%$ maturity decreased significantly over time from cohorts 1974 to 2007 for
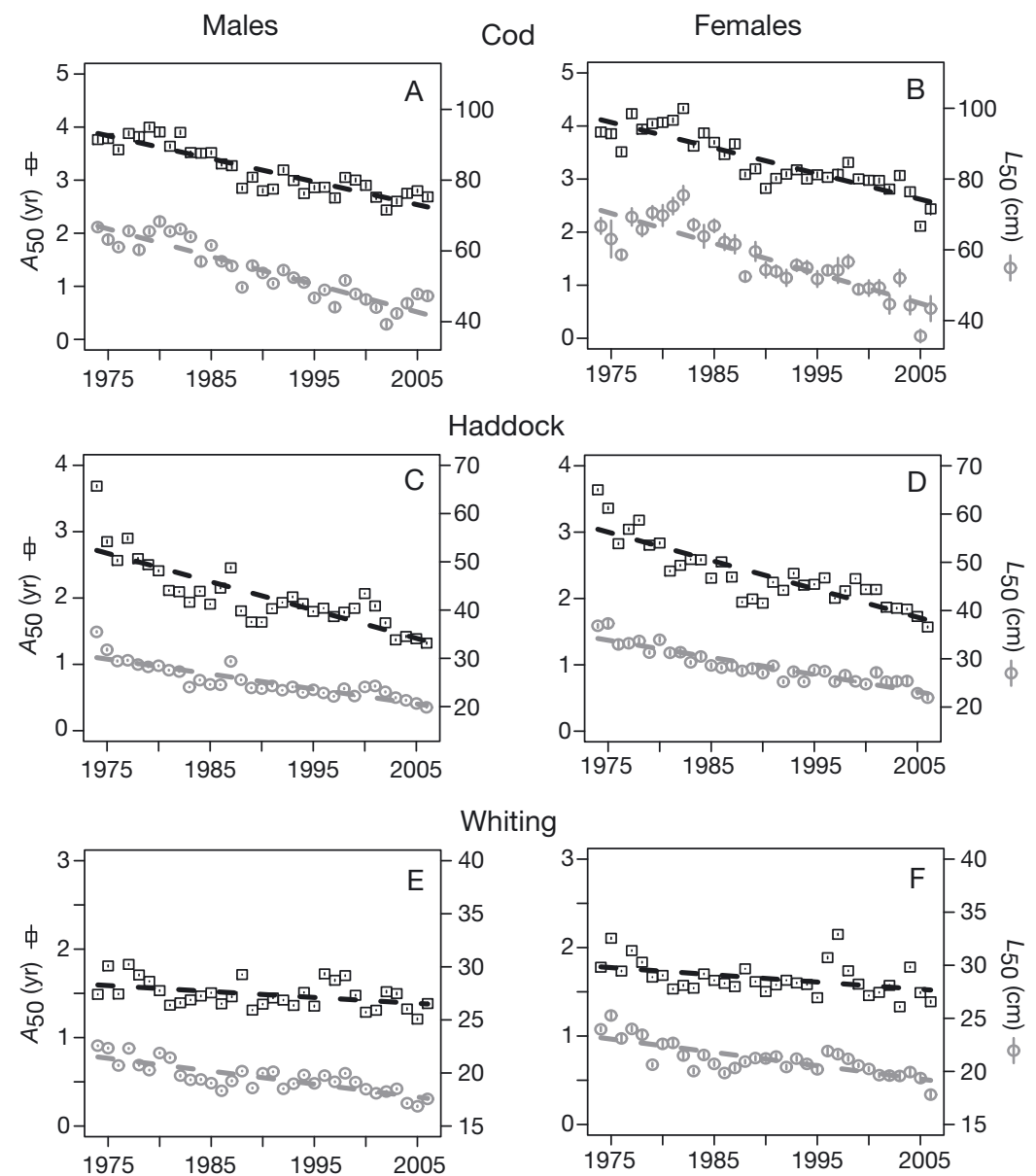

Norway pout
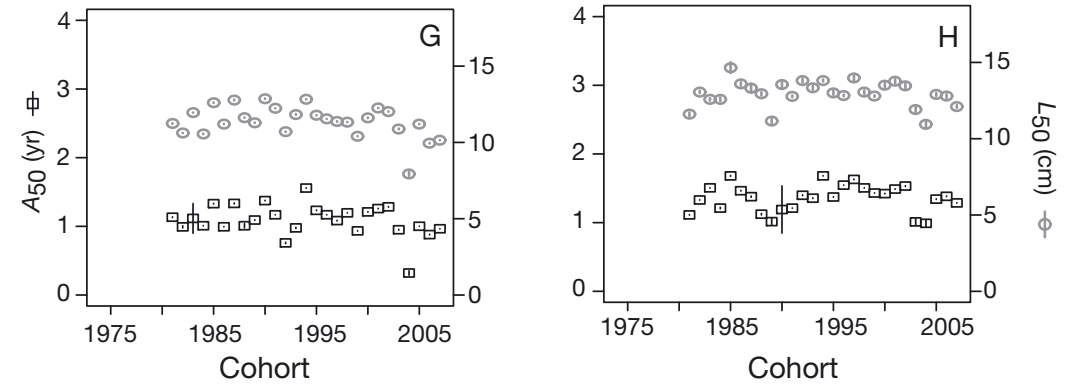


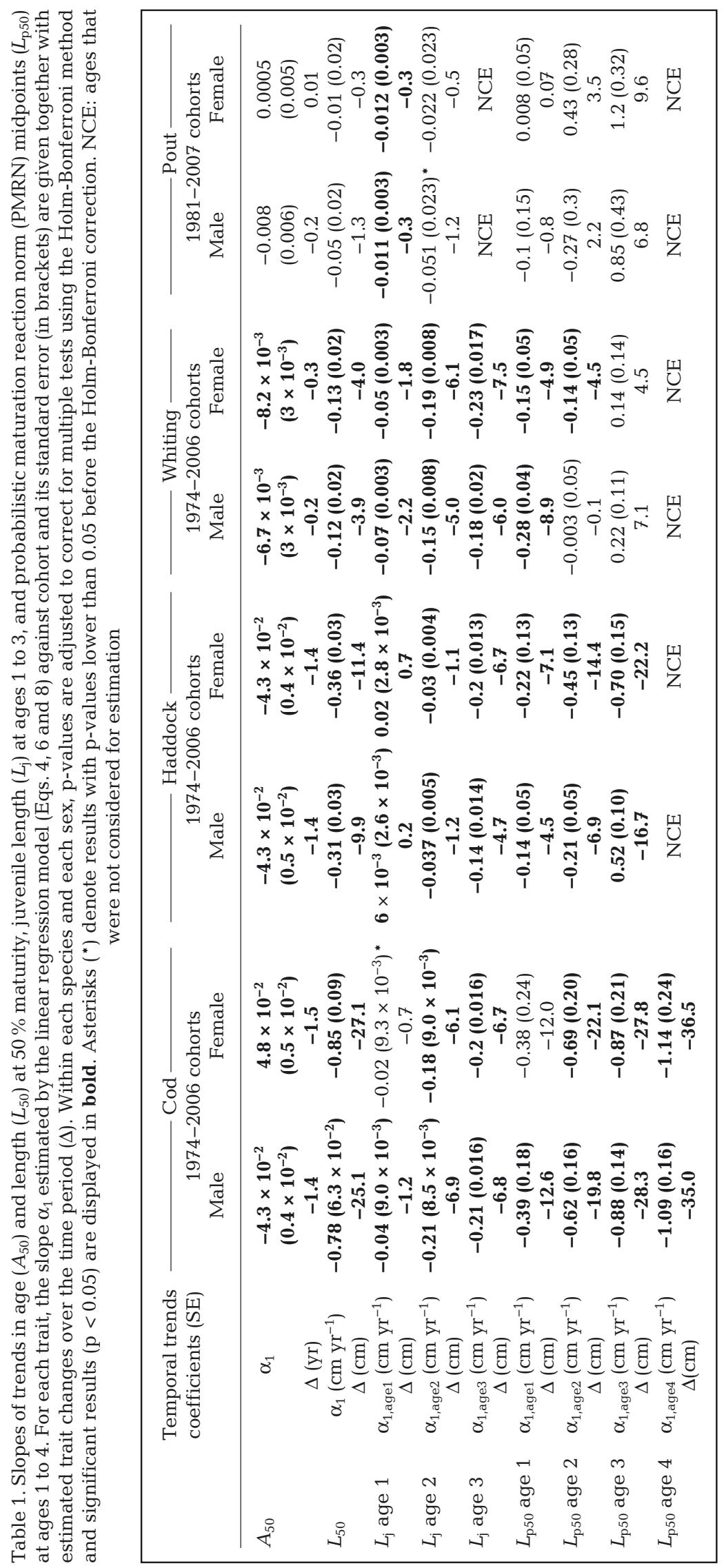

male and female cod, haddock and whiting (Table 1, Fig. 2A-F). No significant change was found for Norway pout over cohorts from 1983 to 2007 (Table 1, Fig. 2G,H). Species rank from the largest to the smallest magnitude of changes was the following: cod, haddock, whiting and Norway pout (Table 1). Short-term fluctuations in $A_{50}$ and $L_{50}$ were generally similar between sexes within species. For cod, $A_{50}$ and $L_{50}$ seemed steady (or even increasing) until 1983 and then steeply decreasing. For haddock, $A_{50}$ steeply decreased between 1974 and 1990, followed by a partial rebound and subsequent steady period between 1991 and 2000, after which it decreased again until 2006, while $L_{50}$ decreased more steadily over the study period. For whiting, the $L_{50}$ temporal dynamic was roughly the same as for haddock $A_{50}$, except for the start of the rebound in 1986, while $A_{50}$ decreased steadily with short-term fluctuations.

\section{Temporal trends in juvenile length-at-age}

Significant temporal trends towards smaller juvenile body length were found for male cod at ages 1 to 3, for female cod at ages 2 and 3, for male and female haddock and whiting at ages 1 to 3 and for male Norway pout at age 1 (Table 1, Fig. 3). Short-term fluctuations in length-at-age were roughly similar across ages and sexes within species. The strongest decline in cod and haddock juvenile length-at-age seemed to occur mainly after 1990. Regardless of species, the amplitude of the decline was lower at younger ages.

\section{Temporal trends in PMRNs}

PMRN isolines of $50 \%$ probability of maturing were estimated for each cohort independently and averaged over cohort decades (Fig. 4). These estimated PMRNs were close to linear 

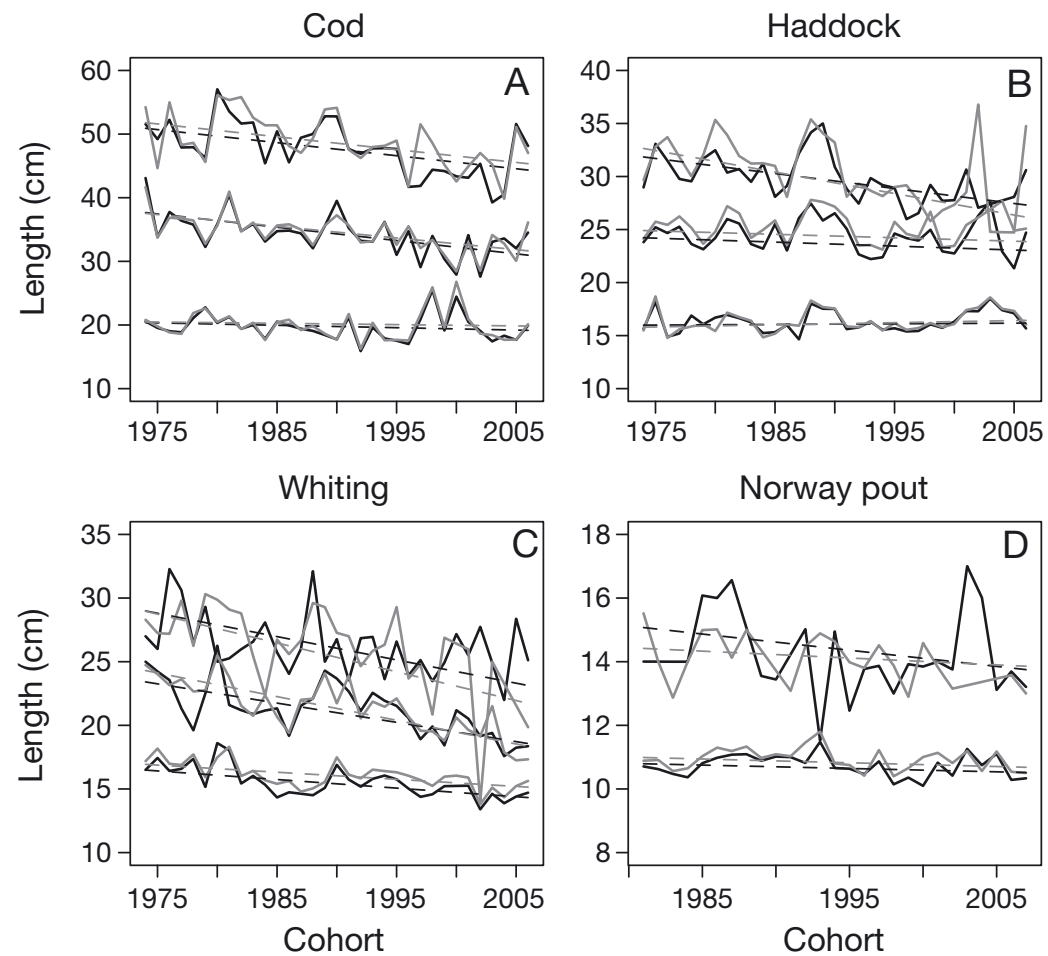

Fig. 3. Times series of mean juvenile length-at-age. Mean juvenile length estimated for male (black solid line) and female (grey solid line) (A) cod, (B) haddock, (C) whiting, and (D) Norway pout, from (bottom to top curve) age 1 to 3 for cod, haddock and whiting, and age 1 to 2 for Norway pout. Straight dashed lines, black for male, grey for female, give the regression lines of length-atage against cohort (partly as a consequence of using age as a continuous variable) and their slope varied from slightly positive to clearly negative so that the size at a certain probability of maturing was slowly increasing or decreasing with age, depending on species and/or time period. For male and female cod and haddock, the probability of maturing increased over time at each age and length, while PMRNs became more negatively sloped (Fig. 4A,B, $\mathrm{C}, \mathrm{D})$. This decrease in PMRN slopes was modelled through the interaction term between age and cohort in model (8), and was significant in all 4 cases (male cod: $F_{4,120}=26.6, p<$ 0.0001 , female cod $F_{4,115}=13.8, \mathrm{p}<$ 0.0001 , male haddock $F_{3,83}=17.7, \mathrm{p}<$ 0.0001 , and female haddock $F_{3,84}=$ 29.9, $\mathrm{p}<0.0001$ ). Meanwhile, cod and haddock average growth slowed down. Consequently, from the 1970s to the 2000s, the average age and size at which individual probability of maturing is $50 \%$ shifted from $3.9 \mathrm{yr}$ and $67.8 \mathrm{~cm}$ to $2.7 \mathrm{yr}$ and $44.6 \mathrm{~cm}$ for male cod, from $4.1 \mathrm{yr}$ and $71.2 \mathrm{~cm}$ to
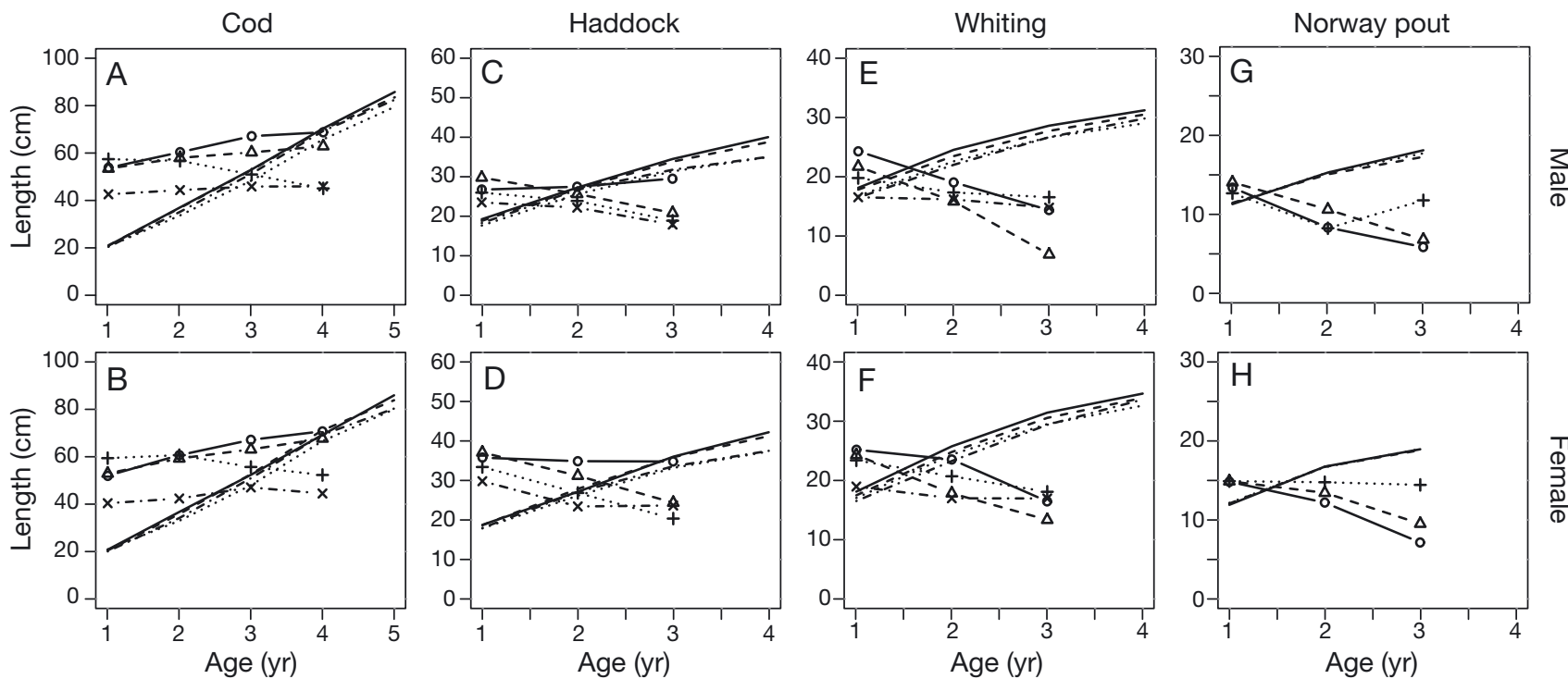

Fig. 4. Temporal trends in probabilistic maturation reaction norms (PMRNs). Probabilistic reaction norm isolines of $50 \%$ probability of maturing (= curve of PMRN midpoints $L_{\mathrm{p} 50}$ at different ages) averaged over cohorts 1974 to 1980 (solid line, open circles), 1981 to 1990 (dashed line, open triangles), 1991 to 2000 (dotted line, + symbols) and 2001 to 2006 (dashed-dotted line, $\times$ symbols) for $(A, C, E)$ male and $(B, D, F)$ female $(A, B) \operatorname{cod},(C, D)$ haddock, $(E, F)$ whiting, and averaged over cohorts 1981 to 1989 (solid line, open circles), 1990 to 1998 (dashed line, open triangles), and 1999 to 2007 (dotted line, + symbols) for (G) male and $(\mathrm{H})$ female Norway pout. $L_{\mathrm{p} 50}$ averages are weighted by the inverse of their bootstrap standard deviations. Same line types without symbols: mean length-at-age of both immature and mature individuals for the corresponding cohorts 
$2.8 \mathrm{yr}$ and $46.1 \mathrm{~cm}$ for female cod, from $2.1 \mathrm{yr}$ and $27.2 \mathrm{~cm}$ to $1.3 \mathrm{yr}$ and $22.7 \mathrm{~cm}$ for male haddock, and from $2.9 \mathrm{yr}$ and $34.6 \mathrm{~cm}$ to $1.7 \mathrm{yr}$ and $24.9 \mathrm{~cm}$ for female haddock. A weaker downward shift in whiting PMRN was observed, while growth decreased slightly as well (Fig. 4E,F). In contrast, female Norway pout, $L_{\mathrm{p} 50}$ at age 2 (Fig. $4 \mathrm{G}, \mathrm{H}$ ) shifted upwards over the study period while male Norway pout $L_{\mathrm{p} 50}$ at age 2 increased between the 1980s and 1990s, and decreased between the 1990s and the 2000s.

The shift in male and female cod and haddock PMRNs can also be seen through the significant downward trends in their midpoint $L_{\mathrm{p} 50}$ at almost all ages (Table 1, Fig. 5A-D for the best age-wise estimate). Significant negative trends in $L_{\mathrm{p} 50}$ were found at ages 1 and 2 for female and at age 1 for male whiting (Table 1, Fig. 5E,F). No trend was found for Norway pout PMRN (Table 1, Fig. 5G,H).

\section{Environmental versus cohort effects on PMRNs}

Not all environmental factors potentially affecting maturation propensity exhibited a temporal trend over the study period (Fig. 6). From 1974 to 2010, significant trends were found in summer water tem-

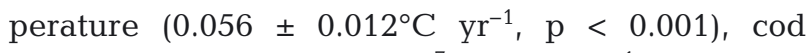
recruitment $\left(-3.8 \pm 0.6 \times 10^{7}\right.$ recruits $\left.\mathrm{yr}^{-1}, \mathrm{p}<0.001\right)$ and whiting recruitment $\left(-1.7 \pm 0.6 \times 10^{8}\right.$ recruits $\left.\mathrm{yr}^{-1}, \mathrm{p}=0.012\right)$. These were therefore selected for analysis of their effect on PMRNs. No significant trend was found in haddock, Norway pout or sandeel recruitment, which were left out from further analyses.

Male cod $L_{\mathrm{p} 50}$ at age 3, male and female haddock $L_{\mathrm{p} 50}$ at age 2 , and male and female whiting $L_{\mathrm{p} 50}$ at age 1 decreased significantly with cohort, while female cod $L_{\mathrm{p} 50}$ at age 3 decreased significantly with temperature experienced at age 0 (Table 2). From cohort 1974 to 2006, the cohort effect explained a decrease of $20.8 \mathrm{~cm}$ in male cod $L_{\mathrm{p} 50}$ at age 3 , and of $8.7 \mathrm{~cm}$ and $14.3 \mathrm{~cm}$, respectively, in male and female haddock $L_{\mathrm{p} 50}$ at age 2. Despite being non-significant, the cohort effect accounted for a reduction of $17.8 \mathrm{~cm}$ in female $\operatorname{cod} L_{\mathrm{p} 50}$ at age 3 versus $5.9 \mathrm{~cm}$ for the significant temperature effect. From cohort 1990 to 2006, the cohort effect explained a decrease of 9.1 and $5.2 \mathrm{~cm}$, respectively, in male and female whiting $L_{\mathrm{p} 50}$ at age 1 . These effects were stronger than the negative cohort effects previously found in male and female whiting $L_{\mathrm{p} 50}$ at age 1 between cohorts 1974 and 2006 (Table 1).
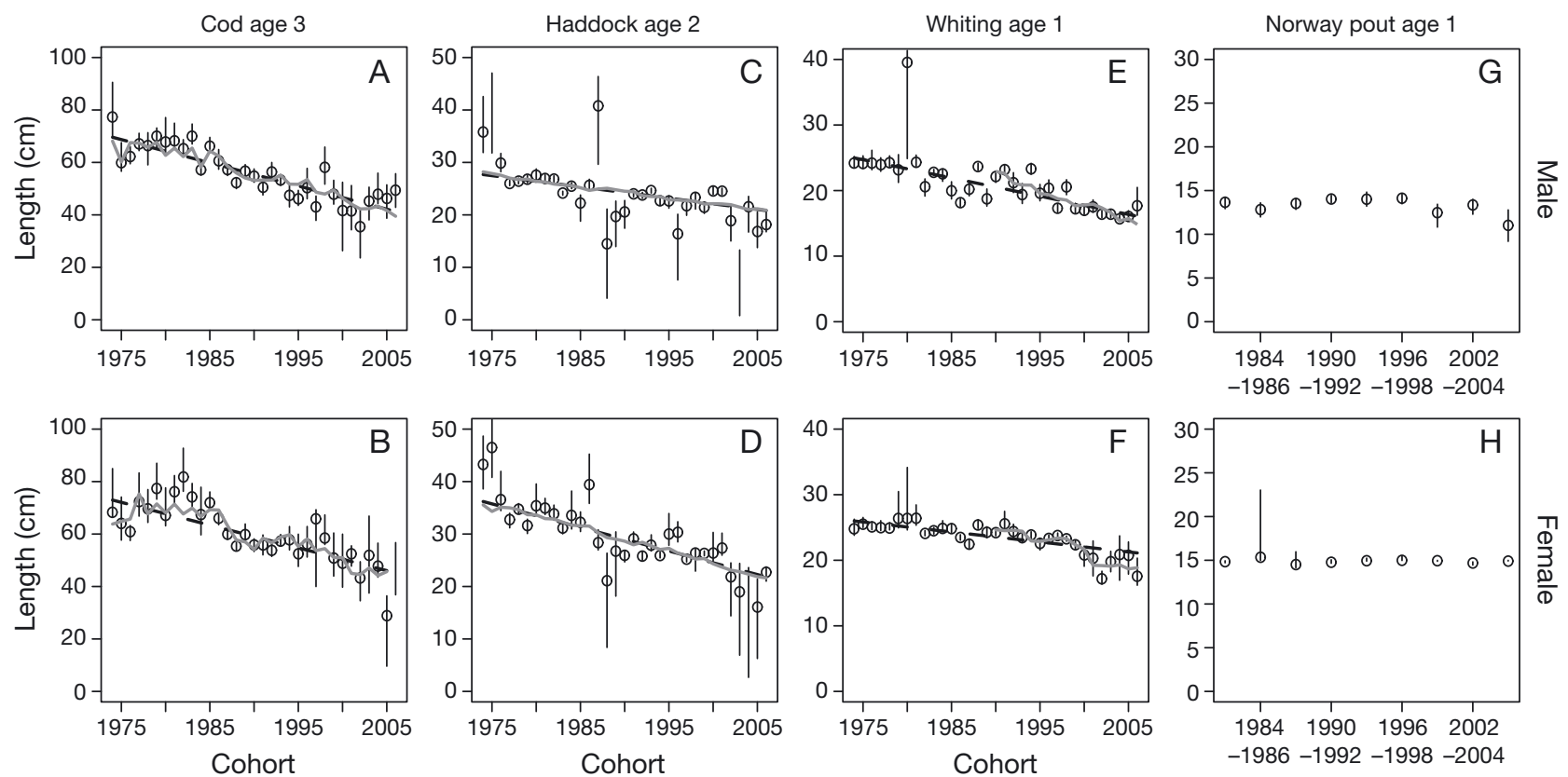

Cohort

Fig. 5. Time series of PMRN midpoints $\left(L_{\mathrm{p} 50}\right)$ at the ages they were best estimated for each species and sex: $(\mathrm{A}, \mathrm{C}, \mathrm{E}, \mathrm{G}) \mathrm{male}$ and $(B, D, F, H)$ female $(A, B)$ cod age $3,(C, D)$ haddock age $2,(E, F)$ whiting age $1,(G, H)$ Norway pout age 1 . Vertical bars give the bootstrap $95 \%$ confidence interval. Dashed black lines give the regression line of $L_{\mathrm{p} 50}$ estimates against cohort, weighted by the inverse of bootstrap standard deviations, whenever significant. Solid grey lines give the predicted $L_{\mathrm{p} 50}$ from the principal component regression including cohort and environmental effects 

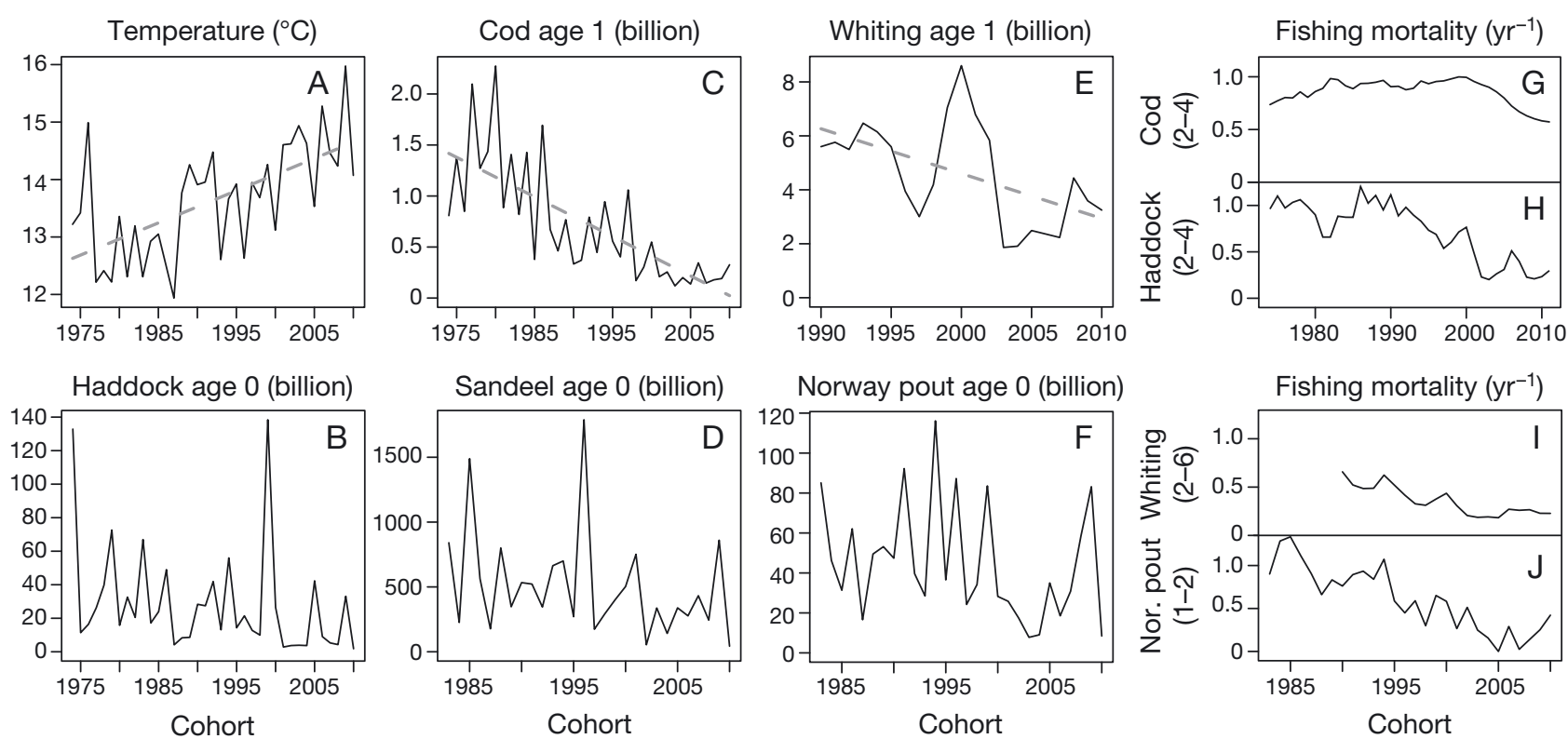

Fig. 6. Time series of environmental factors and fishing mortalities. (A) Summer sea surface temperature. Recruitment indices of (B) haddock at age 0, (C) cod at age 1, (D) sandeel at age 0, (E) whiting at age 1 and (F) Norway pout at age 0 . Dashed grey lines are regressions lines whenever a significant time trend at the $5 \% \alpha$-risk is found. Average fishing mortality of $(\mathrm{G})$ cod ages 2-4, (H) haddock ages 2-4, (I) whiting ages 2-6 and (J) Norway pout ages 1-2

\section{Effect of life-history parameters on the magnitude of maturation change}

Cod, haddock, whiting and Norway pout rank along a life-history strategy gradient from fast growth rate, low reproductive investment, and late maturation at large size to slow growth rate, strong reproductive investment and early maturation at small size, when the relative change in $L_{\mathrm{p} 50}$ increases from strongly negative to no trend (Fig. 7).

\section{DISCUSSION}

\section{Temporal trends in age $A_{50}$ and length $L_{50}$ at $50 \%$ maturity}

From cohort 1974 to 2006, we detected temporal trends towards lower $A_{50}$ and $L_{50}$ in cod, haddock and whiting. Rochet (2000b) focused on the same stocks over the period 1983 to 1995 and found the same trends for cod and haddock, but no trend for whiting, and a significant increasing trend in age at maturity for Norway pout. These 2 discrepancies might arise from extending the time period considered. For whiting, the detected decrease was relatively slow over the period 1974 to 2001 and would have gone unnoticed over the period 1983 to 1995. For Norway pout, we also observed an increase in $A_{50}$ from 1983 to 1995, but it decreased back to its previous level afterwards, so that no trend was detectable over the whole period. In contrast, Lambert et al. (2009) found negative temporal trends in Norway pout age and length at maturity over cohorts 1983 to 2006. However, these trends were weak and driven by the last studied cohorts (2003 to 2005) that were characterized by low abundance and densities. The increase in the proportion of mature individuals at age 1 was no longer significant when removing these last cohorts. In accordance with this finding, our estimated age $A_{50}$ and length $L_{50}$ at $50 \%$ maturity for Norway pout both dropped around 2004, but they rebounded afterwards.

We accounted for the contribution of 3 non-mutually exclusive mechanisms to the temporal trends in maturity ogives: a demographic effect, a plastic response to temporal variations in individual growth rates and/or environmental factors, and an evolutionary change in maturation timing (Fig. 1). To this end, we identified trends in maturation propensity that are independent of demography and growth-dependent plasticity using PMRNs, and then investigated growthindependent plasticity in maturation by correlating PMRN midpoints with environmental variables. In the following, we will discuss these 2 points and interpret residual trends in maturation propensity related to a cohort effect as most likely evolutionary changes. Furthermore, we will retrospectively evaluate the impact of growth-dependent plasticity on $A_{50}$ and $L_{50}$ by qualitative reasoning. 
Table 2. Regression coefficients and their standard errors (SE) for cod $L_{\mathrm{p} 50}$ at age 3 , haddock $L_{\mathrm{p} 50}$ at age 2 and whiting $L_{\mathrm{p} 50}$ at age 2, obtained from transforming back to the original set of axes the principal component regression coefficients and their SEs. For each coefficient, $t$-statistic value $(t)$, uncorrected and corrected $p$-values associated with 25 degrees of freedom for cod, 29 for haddock, and 11 for whiting, and the amplitude $\left(\Delta L_{\mathrm{p} 50}\right)$ of the change in $L_{\mathrm{p} 50}$ due to each effect over the study periods are given. Corrected p-values are adjusted to correct for multiple tests using the Holm-Bonferroni method and significant coefficients (corrected p-value $<0.05$ ) are displayed in bold. Asterisks $\left(^{*}\right.$ ) denote results with p-values lower than 0.05 before the Holm-Bonferroni correction.

\begin{tabular}{|c|c|c|c|c|c|c|}
\hline Effect & Sex & Coefficient (SE) & $t$ & $\mathrm{p}$ & Corrected p & $\Delta L_{\mathrm{p} 50}(\mathrm{~cm})$ \\
\hline \multicolumn{7}{|l|}{ Cod Age 3 (cohort 1974-2006) } \\
\hline Cohort $\left(\mathrm{cm} \mathrm{yr}^{-1}\right)$ & $\mathbf{M}$ & $-0.63(0.23)$ & -2.76 & 0.009 & 0.037 & -20.8 \\
\hline Temperature age $0\left(\mathrm{~cm}^{\circ} \mathrm{C}^{-1}\right)$ & M & $-1.41(1.02)$ & -1.38 & 0.098 & 0.451 & -2.6 \\
\hline Recruitment age $0\left(\mathrm{~cm}\right.$ recruit $\left.^{-1}\right)$ & $\mathrm{M}$ & $2.24 \times 10^{-9}\left(2.43 \times 10^{-9}\right)$ & 0.92 & 0.812 & 1.000 & -2.9 \\
\hline Temperature age $1\left(\mathrm{~cm}^{\circ} \mathrm{C}^{-1}\right)$ & M & $-1.91(1.1)$ & -1.74 & 0.055 & 0.279 & -3.5 \\
\hline Recruitment age $1\left(\mathrm{~cm}\right.$ recruit $\left.^{-1}\right)$ & M & $-1.93 \times 10^{-9}\left(2.44 \times 10^{-9}\right)$ & -0.79 & 0.222 & 0.870 & 2.5 \\
\hline Temperature age $2\left(\mathrm{~cm}^{\circ} \mathrm{C}^{-1}\right)$ & M & $0.08(1.20)$ & 0.06 & 0.525 & 1.000 & 0.1 \\
\hline Recruitment age $2\left(\mathrm{~cm}\right.$ recruit $^{-1}$ ) & M & $1.19 \times 10^{-9}\left(2.37 \times 10^{-9}\right)$ & 0.50 & 0.687 & 1.000 & -1.5 \\
\hline Cohort $\left(\mathrm{cm} \mathrm{yr}^{-1}\right)$ & $\mathrm{F}$ & $-0.54(0.26)^{*}$ & -2.08 & $0.031^{*}$ & 0.119 & $-17.8^{*}$ \\
\hline Temperature age $0\left(\mathrm{~cm}^{\circ} \mathrm{C}^{-1}\right)$ & $\mathbf{F}$ & $-3.18(1.18)$ & -2.69 & 0.010 & 0.043 & -5.9 \\
\hline Recruitment age $0\left(\mathrm{~cm}\right.$ recruit $\left.^{-1}\right)$ & $\mathrm{F}$ & $-1.80 \times 10^{-9}\left(2.80 \times 10^{-9}\right)$ & -0.64 & 0.266 & 0.525 & 2.3 \\
\hline Temperature age $1\left(\mathrm{~cm}^{\circ} \mathrm{C}^{-1}\right)$ & $\mathrm{F}$ & $-2.50(1.30)$ & -1.92 & 0.040 & 0.131 & -4.6 \\
\hline Recruitment age 1 (cm recruits ${ }^{-1}$ ) & $\mathrm{F}$ & $-2.77 \times 10^{-9}\left(2.82 \times 10^{-9}\right)$ & -0.98 & 0.174 & 0.504 & 3.5 \\
\hline Temperature age $2\left(\mathrm{~cm}^{\circ} \mathrm{C}^{-1}\right)$ & $\mathrm{F}$ & $-3.0(1.38)$ & -2.16 & 0.270 & 0.119 & -5.5 \\
\hline Recruitment age $2\left(\mathrm{~cm}\right.$ recruit $\left.^{-1}\right)$ & $\mathrm{F}$ & $1.18 \times 10^{-9}\left(2.72 \times 10^{-9}\right)$ & 0.43 & 0.663 & 0.666 & -1.5 \\
\hline \multicolumn{7}{|l|}{ Haddock Age 2 (cohort 1974-2006) } \\
\hline Cohort $\left(\mathrm{cm} \mathrm{yr}^{-1}\right)$ & $\mathbf{M}$ & $-0.25(0.08)$ & -3.02 & 0.006 & 0.008 & -8.6 \\
\hline Temperature age $0\left(\mathrm{~cm}^{\circ} \mathrm{C}^{-1}\right)$ & M & $0.13(0.63)$ & 0.21 & 0.58 & 1.00 & 0.3 \\
\hline Temperature age $1\left(\mathrm{~cm}^{\circ} \mathrm{C}^{-1}\right)$ & M & $0.31(0.66)$ & 0.48 & 0.68 & 1.00 & 0.6 \\
\hline Cohort $\left(\mathrm{cm} \mathrm{yr}^{-1}\right)$ & $\mathbf{F}$ & $-0.41(0.09)$ & -4.48 & $<0.001$ & $<0.001$ & -14.3 \\
\hline Temperature age $0\left(\mathrm{~cm}^{\circ} \mathrm{C}^{-1}\right)$ & $\mathrm{F}$ & $-0.14(0.72)$ & -0.20 & 0.424 & 0.497 & -0.3 \\
\hline Temperature age $1\left(\mathrm{~cm}^{\circ} \mathrm{C}^{-1}\right)$ & $\mathrm{F}$ & $-0.52(0.75)$ & -0.69 & 0.253 & 0.497 & -1.0 \\
\hline \multicolumn{7}{|l|}{ Whiting Age 1 (cohort 1990-2006) } \\
\hline Cohort $\left(\mathrm{cm} \mathrm{yr}^{-1}\right)$ & $\mathbf{M}$ & $-0.54(0.1)$ & -5.59 & $<0.001$ & $<0.001$ & -9.1 \\
\hline Temperature age $0\left(\mathrm{~cm}^{\circ} \mathrm{C}^{-1}\right)$ & M & $0.22(0.56)$ & 0.40 & 0.650 & 1.000 & 0.2 \\
\hline Recruitment age $0\left(\mathrm{~cm}\right.$ recruit $\left.^{-1}\right)$ & M & $-5.81 \times 10^{-11}\left(2.54 \times 10^{-10}\right)$ & 0.23 & 0.588 & 1.000 & -0.2 \\
\hline Temperature age $1\left(\mathrm{~cm}^{\circ} \mathrm{C}^{-1}\right)$ & M & $0.63(0.57)$ & 1.10 & 0.852 & 1.000 & 0.6 \\
\hline Recruitment age $1\left(\mathrm{~cm}\right.$ recruit $^{-1}$ ) & M & $-9.42 \times 10^{-11}\left(2.50 \times 10^{-10}\right)$ & -0.38 & 0.357 & 1.000 & 0.3 \\
\hline Cohort $\left(\mathrm{cm} \mathrm{yr}^{-1}\right)$ & $\mathbf{F}$ & $-0.31(0.08)$ & -3.99 & 0.001 & 0.005 & -5.2 \\
\hline Temperature age $0\left(\mathrm{~cm}^{\circ} \mathrm{C}^{-1}\right)$ & $\mathrm{F}$ & $-0.44(0.42)$ & -1.04 & 0.160 & 0.640 & -0.4 \\
\hline Recruitment age $0\left(\mathrm{~cm}\right.$ recruit $\left.^{-1}\right)$ & $\mathrm{F}$ & $-9.71 \times 10^{-11}\left(1.83 \times 10^{-10}\right)$ & -0.53 & 0.304 & 0.640 & 0.3 \\
\hline Temperature age $1\left(\mathrm{~cm}^{\circ} \mathrm{C}^{-1}\right)$ & $\mathrm{F}$ & $-0.43(0.43)$ & -1.02 & 0.166 & 0.640 & -0.4 \\
\hline Recruitment age $1\left(\mathrm{~cm} \mathrm{recruit}^{-1}\right)$ & $\mathrm{F}$ & $-4.01 \times 10^{-10}\left(1.76 \times 10^{-10}\right)$ & 2.28 & 0.978 & 0.978 & -1.1 \\
\hline
\end{tabular}

\section{Processes at stake in temporal trends in maturity ogives}

\section{Temporal trends in PMRNs}

Along with the changes in maturity ogives, PMRN midpoints significantly decreased over time in cod, haddock and whiting. A PMRN describes a conditional probability, i.e. the probability that an immature individual matures at a given age and size, conditional on having survived and grown until that age-size point. Under some assumptions about individual growth and survival against which the method is robust (see 'PMRNs: estimation method' above), PMRNs therefore allow depicting the maturation process independently from the influence of survival and growth in contrast with maturity ogives. Since cod, female whiting and haddock PMRNs have varied, demography and growth-dependent plasticity cannot fully explain temporal changes in their maturity ogives: changes in maturation propensity due to growth-independent plasticity in response to environmental conditions and/or fisheries-induced evolution in maturation are likely to have also played a role. Negative temporal trends in PMRN midpoints have already been observed for inshore haddock along the Scottish coast (Wright et al. 2011a, but see Devine \& Heino 2011) as well as for other cod stocks (Heino et al. 2002b, Olsen et al. 2004, 2005, Yoneda \& Wright 2004, Pardoe et al. 2009, Vainikka et al. 2009). 

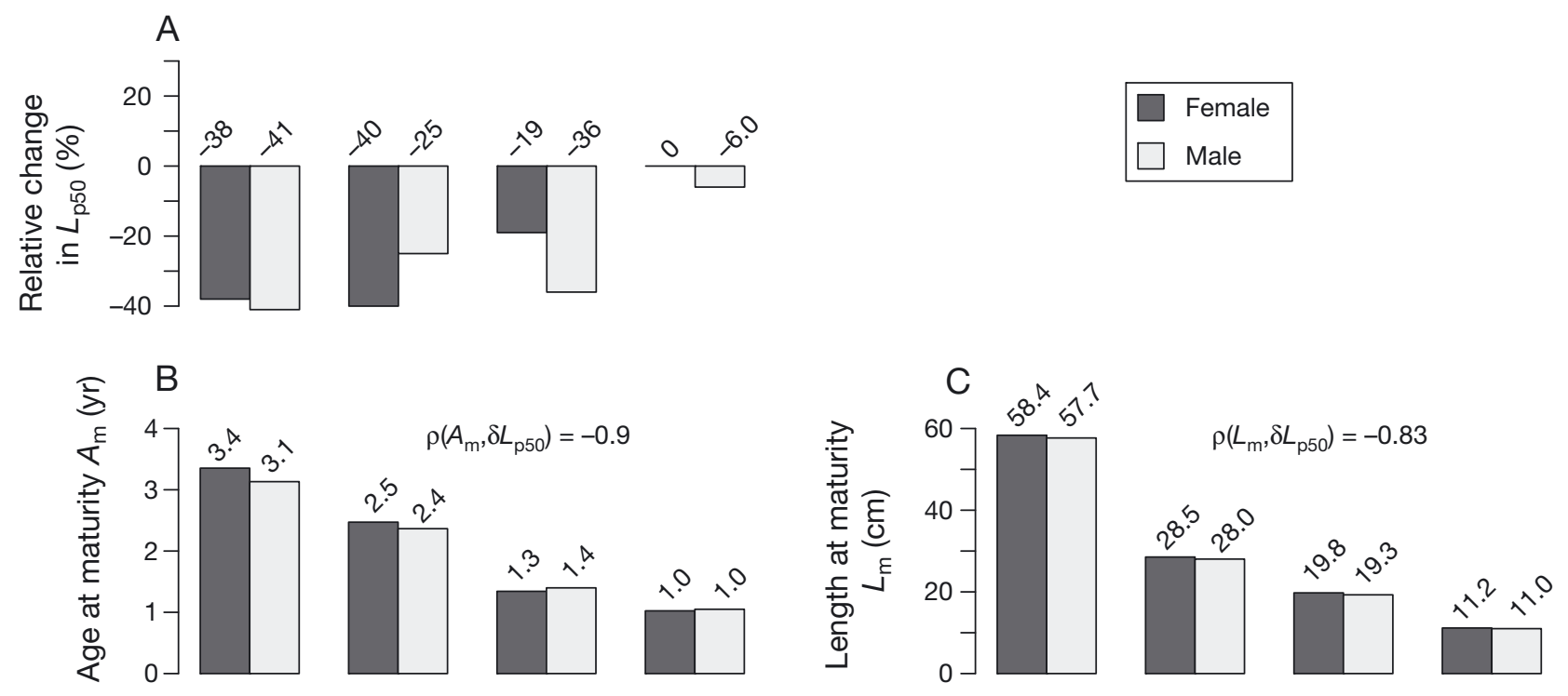

$\mathrm{D}$

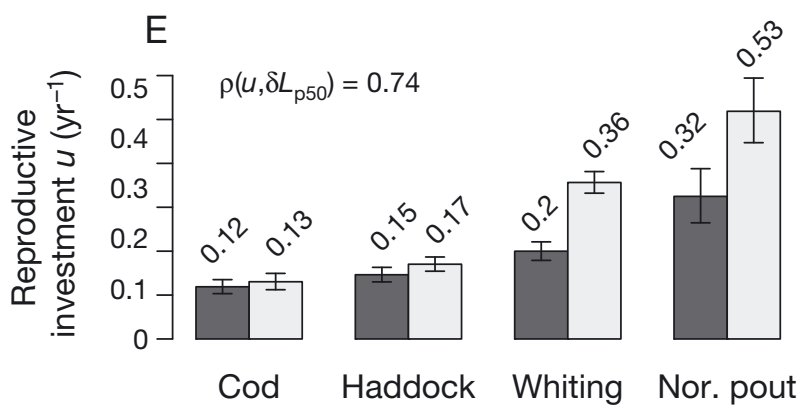

Fig. 7. Interspecies comparison of $(\mathrm{A})$ relative change in $L_{\mathrm{p} 50}\left(\delta L_{\mathrm{p} 50}\right)$ with life-history parameters estimated at the beginning of the study periods: mean (B) age $A_{\mathrm{m}}$ and (C) length $L_{\mathrm{m}}$ at maturity, (D) juvenile growth rate $g_{\mathrm{j}}$ and (E) reproductive investment $u$. Dark grey: females; light grey: males. $\rho$ : Spearman correlation coefficient between $\left(\delta L_{\mathrm{p} 50}\right)$ and the parameter. Error bars: $95 \%$ confidence intervals

More generally, most exploited stocks subject to PMRN analysis exhibited similar trends in maturation propensity (Jørgensen et al. 2007, Kuparinen \& Merilä 2007, Hutchings \& Fraser 2008). Therefore, the phenomenon is observed in phylogenetically different species located in different environments, suggesting that it is caused by a common and global driver. Increase in water temperature generated by global warming, decrease in population biomass due to fishing and fisheries-induced evolution are thus the most plausible explanatory factors.

\section{Growth-independent plasticity versus fisheries-induced evolution}

Rise in temperature, systematic increase in food abundance, release of trophic competition and relaxation of social pressure may all cause a direct plastic response of the maturation rate (Kraak 2007). Among the potential sources of growth-independent plasti- city examined, only temperature had a significant effect on female cod maturation; temperature experienced at age 0 had a significant negative effect on female $\operatorname{cod} L_{\mathrm{p} 50}$ at age 3 , in agreement with earlier work (Wright et al. 2011b, Neuheimer \& Grønkjær 2012). Previous findings for North Sea plaice and sole have also shown that elevated temperatures may accelerate maturation (Grift et al. 2003, Mollet et al. 2007). Evidence of short-term temperature effects can also be found in the time series: around the years 1987 to 1989, temperatures exhibited a peak (Fig. 6A), which is concomitant with some drops in cod and haddock PMRN midpoints (Fig. 5A-D). Such a sudden shift in PMRN midpoints is more consistent with a plastic response of maturation to environmental fluctuations than with fisheries-induced evolution, which is more likely to operate gradually (Marshall \& McAdam 2007, Heino \& Dieckmann 2008).

Long-term negative temporal trends in male cod, haddock and whiting PMRNs were associated with a cohort effect in the PCRs despite the inclusion of the 
most plausible environmental factors capable of generating growth-independent plasticity in maturation. Since these environmental factors cannot explain the totality of the temporal trends in PRMNs, this suggests fisheries-induced evolution, in agreement with Neuheimer \& Grønkjær (2012) and Neuheimer \& Taggart (2010) for haddock and Wright et al. (2011b) for male cod. For female cod, the cohort effect was no longer significant after the inclusion of the environmental variables in the analysis, although it was significant before correction for multiple testing and it explained the largest part of the temporal change in PMRNs. This could originate from overlooking North Sea cod population structure. Wright et al. (2011b) showed significant decreases of both male and female cod PMRNs in 3 subpopulations of the North Sea, with a much faster decline in the north-western and southern subpopulations than in the north-eastern one, which coincides with a near collapse of cod spawning stock biomass in the 2 first subpopulations. The trends in cod PMRNs estimated at the scale of the whole North Sea in this study are thus likely to be underestimated due to a bias towards the most abundant subpopulation, i.e. the north-eastern subpopulation, in which the decline in PMRNs has been slow. However, this does not explain the discrepancy in terms of cohort effect found between male and female cod. A possible answer lies in the potential effect of fishing mortality on sex ratio; in north-east arctic cod, fishing has been shown to increase the proportion of mature males (Jakobsen \& Ajiad 1999). North Sea female cod in the less abundant subpopulations (north-west and south) could have been even scarcer than males due to fishing effects on sex ratio, thus resulting in PRMN trends at the scale of the whole North Sea more strongly biased for females than for males. For Norway pout, no analysis of the influence of environmental factors could be performed because of the lack of data, but the stability of the PMRNs can be qualitatively interpreted. Cod, haddock and whiting are important predators of Norway pout in the North Sea. The total biomass of these species decreased strongly over the last decades, which probably relaxed the predation mortality experienced by Norway pout (Sparholt et al. 2002). In addition, fishing mortality steeply declined over the study period for this species (Fig. 6J). Under lower mortality, individuals benefit from maturing later, so that age at maturation may have evolved towards older ages and counteracted fisheries-induced selection towards earlier maturation (Gårdmark \& Dieckmann 2006).

In conclusion, for male cod, haddock and whiting, demography, growth-dependent plasticity and growth-independent plasticity in response to environmental factors are not sufficient to explain the temporal trends detected in $A_{50}$ and $L_{50}$. The residual trends in PMRNs associated with a cohort effect are compatible with the hypothesis of fishing-induced evolution for these species (Law 2007). For female cod, our results suggest that warmer temperature may have driven a plastic increase in maturation probability at age and size but should be treated with caution due to the potential influence of stock structure. Finally, for Norway pout, no change occurred either in maturity ogives or in PMRNs.

Further insights into the role of growth

The different processes affecting maturity ogives are not mutually exclusive, and all of them may have contributed to temporal trends in $A_{50}$ and $L_{50}$. Notably, the intensity and the direction of the demographic effect and growth-dependent plasticity in maturation are not readily obtained from PMRN analyses, which only filter them out. It is, however, possible to outline qualitative expectations about the influence of growth on maturity ogives, based on the fact that the relationship between juvenile growth and observed individual ages and sizes at maturation in the population, and thus $A_{50}$ and $L_{50}$, depends on the interplay between the geometry of the PMRNs and the length-at-age curves. For roughly linear PMRNs such as in our case, a negatively sloped PMRN implies that juvenile growth rate is positively correlated with observed length at maturation, whereas the correlation is negative for a positively sloped PMRN. The sign of the correlation between observed age at maturation and juvenile growth rate depends on how growth trajectories approach the PMRN: the correlation is positive when they approach the PMRN from above, negative from below (Fig. 8) (Heino \& Dieckmann 2008, Marty et al. 2011).

Therefore, a compensatory response, that is earlier maturation and thus lower $A_{50}$ related to faster growth favoured by the relaxation of trophic competition due to fishing, is possible if the PMRN is approached by juvenile growth trajectories from below, which was the case for all species. However, opposite to the compensatory response expectation, juvenile length-at-age decreased for the 3 stocks that exhibited changes in maturity ogives. Furthermore, as explained above, the direction of the related change in observed length at maturation depends then on the slope of the PMRN (Fig. 4). Slower juvenile growth should result in an increase in observed 

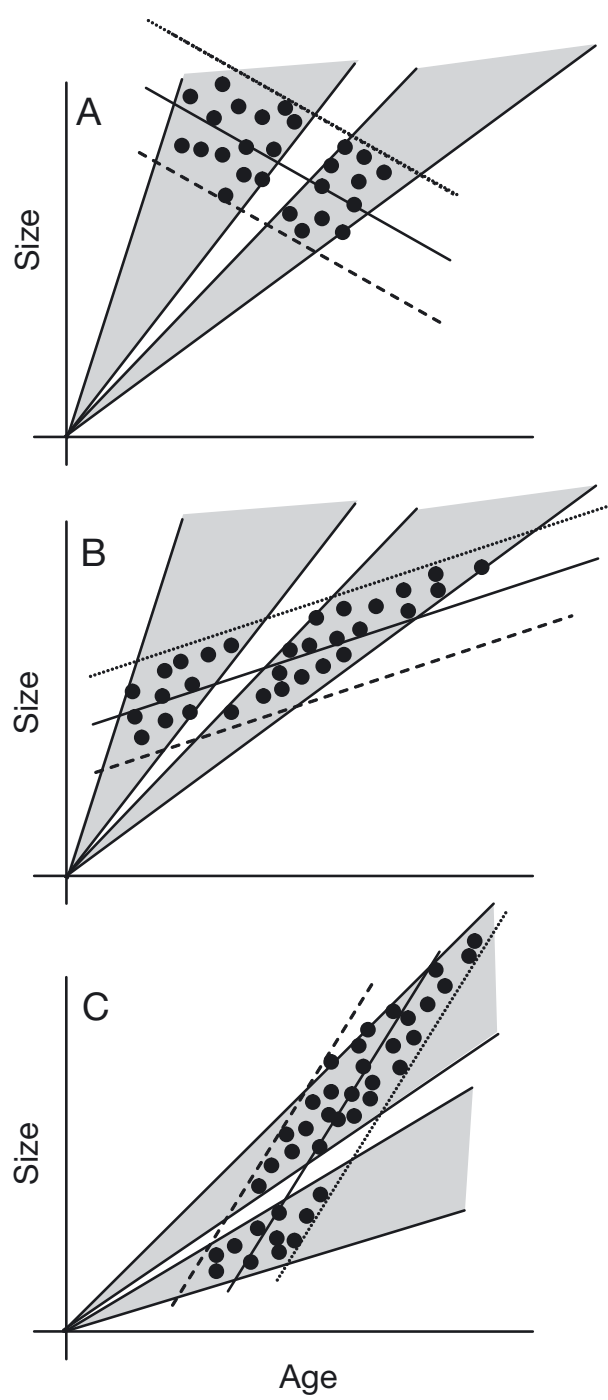

Fig. 8. Relationship between juvenile growth and observed ages and sizes at maturation (represented by black dots) resulting from the interplay between the geometry of the probabilistic maturation reaction norm (PMRN), illustrated by linear contour lines corresponding to $5 \%$ (dashed), $50 \%$ (continuous) and 95\% (dotted) probability of maturing, and juvenile length-at-age curves (described by grey areas). (A) For a negatively sloped PMRN approached from below by length-at-age curves, faster growth rates (upper grey area) result in larger sizes at maturation and younger ages at maturation. (B) For a positively sloped PMRN approached from below by length-at-age curves, faster growth rates result in younger ages at maturation and smaller sizes at maturation. (C) When length-at-age curves approach the PMRN from above, which is possible for a positively sloped PMRN only, faster growth rates result in older ages at maturation and larger sizes at maturation

length at maturation when PMRNs are positively sloped, i.e. for cod and male haddock (Fig. 4, cohorts 1974 to 1980), and a decrease in observed length at maturation when PMRNs are negatively sloped, i.e. for whiting and female haddock (Fig. 4, cohorts 1974 to 1980). These expectations are inconsistent with the decrease in $A_{50}$ and $L_{50}$ in cod and male haddock, while they are consistent with the decreasing $L_{50}$ in whiting and female haddock. Consequently, growthdependent plasticity has probably counteracted the effect of other maturation determinants that drove $A_{50}$ and $L_{50}$ downwards in cod and male haddock. In contrast, growth-dependent plasticity probably contributed to trends towards lower $L_{50}$ in whiting and female haddock. For the latter, this reasoning should be tempered, as the decline in $L_{50}$ of female haddock occurred mainly during the period 1975 to 1990 , whereas juvenile lengths at age mainly decreased after 1990. For Norway pout, the stability of $A_{50}$ and $L_{50}$ appears consistent with the weak change in length-at-age and the relative stability of PMRNs.

\section{Strengths and limitations of the approach}

Our findings should be interpreted with caution owing to the assumptions underlying our approach and the availability of data for potential relevant explanatory factors.

\section{The PMRN approach}

Firstly, age and size are proxies for the physiological determinants of maturation decision. Although the probabilistic nature of PMRNs can virtually encompass any within-cohort source of maturation variation, when it comes to between-generation variation and long-term PMRN trends, any physiological or environmental variables that underwent a temporal trend could be the causal agent (temperature, Morita \& Fukuwaka 2007, Uusi-Heikkilä et al. 2011; social structure, Hutchings et al. 1999; body condition, Grift et al. 2007). The question then boils down to whether all potential drivers of maturation that steadily changed over time were considered. We considered all but one of these factors in our analyses, and thus it seems unlikely that we missed an environmental change as important as one able to drive the strong steady decrease in age and size at maturation detected in these stocks as well as in many other ones. However, we omitted body condition, which is known to affect maturation probability (Bernardo 1993, Uusi-Heikkilä et al. 2011). When adding it as a third dimension in PMRN estimation, empirical studies on North Sea sole and plaice showed that a temporal increase in condition had a significant negative effect on PMRN, although it could not explain the whole 
temporal trend in maturation (Grift et al. 2007, Mollet et al. 2007). Unfortunately, we could not include such an index in our analyses because individual weights were not available. This may have resulted in underestimating the downward temporal trend in cod PMRNs, since body condition has significantly decreased in recent years (Yoneda \& Wright 2004). It is worth noting, however, that our analyses included the influence of food (prey) abundance, which is one of the main drivers of body condition.

Secondly, we estimated juvenile growth trajectories using mean length-at-age for each cohort, implying that only 1 growth trajectory leads to a particular combination of age and length. Yet, different individual growth trajectories may lead to the same age and length combination. It has been shown that past individual growth history influences maturation probability independently from age and size, with most recent growth condition (just before the age at which probability of maturing is calculated) being the most determinant factor (Morita \& Fukuwaka 2006). Individual growth trajectories can be back-calculated from scale or otolith reading (Engelhard et al. 2003, Baulier \& Heino 2008, Mollet et al. 2010), but again this information was not available.

Finally, to investigate the contribution of growthindependent plasticity in PMRN shifts, the collinearity between explanatory variables was accounted for by using PCR. However, inferring firm causation from the significance of effects is not possible, since a correlation between 2 trended variables, here the PMRN midpoints and any explanatory factor, can always arise from a hidden confounding factor responsible for both trends. This issue holds for cohort effects as well as for environmental effects. In conclusion, PMRN analysis cannot provide direct evidence of evolutionary changes but can only assess whether, using the best available knowledge of factors influencing maturation and of environmental changes, it is compatible with the evolutionary hypothesis (Law 2007).

\section{Temporal trends}

Other statistical methods, such as generalized additive models, could have been appropriate to describe more precisely temporal variations in $A_{50}$, $L_{50}$, length-at-age, and $L_{\mathrm{p} 50}$. However, our aim was not to precisely describe how these estimates vary over time but to assess and statistically test the overall direction and amplitude of changes over the study period. Linear regression allows modelling variations with a unique parameter that is easier to interpret than multiple parameters resulting from more sophisticated models. In addition, the trends we modelled were monotonous with small variations resulting in normally distributed residuals without any obvious pattern along the time axis, which justified using a linear model.

\section{Population structure}

We did not document within-stock variability in maturation trends potentially associated with population structure, and therefore possibly overlooked local specificities in terms of the responsible processes. Earlier studies have shown variations in trends in maturation probability among sub-populations of North Sea cod and haddock. Wright et al. (2011b) found a strong decline in $L_{\mathrm{p} 50}$ in the southern and north-western subpopulations of North Sea cod, and a mild decrease in the north-eastern subpopulation, the difference being attributed to stronger selection for early maturing genotypes in the 2 former. Likewise, Wright et al. (2011a) showed that the magnitude of changes in maturation probability was greater in western than eastern North Sea haddock.

\section{Extensions}

Beyond the evidence for evolutionary changes, there is also a suggestion of fishing as the selective agent. Our analysis provides no direct evidence that fishing has generated the selective pressure responsible for the observed, potentially evolutionary, trends. In order to investigate this question more thoroughly, a complementary approach would be to estimate the strength of selection generated by fishing by comparing the age and size at maturation distribution before and after fishing, based on the selectivity of the fishery (Law 2000). Rowell (1993) estimated selection differentials for North Sea cod using a population model and showed that late-maturing fish were expected to be at a strong disadvantage. The body of evidence would be more complete with an empirical analysis of selection differential due to fishing for all 4 North Sea gadid stocks.

In addition, we estimated temporal changes in juvenile length-at-age to interpret temporal changes in maturation, but did not disentangle the potential mechanisms involved in growth long-term trends, which are the same as the ones considered for maturity: demography, plasticity and evolution. 


\section{Evolutionary sensitivity}

Our comparison between relative changes in PMRN midpoints and life-history parameters across the 4 gadid stocks showed that species with late maturation at large size, fast growth rate and weak reproductive investment exhibited larger changes in maturation propensity. These results empirically corroborate the theoretical expectations about the influence of life history on fisheries-induced evolutionary changes in maturation (Heino \& Godø 2002, Ernande et al. 2004). However, exploitation patterns can also influence the direction and strength of the maturation evolutionary response. Cod and haddock were exposed to fairly similar average fishing intensities at the beginning of the time series. Yet results from theoretical studies suggest that, at constant average intensity, exploitation patterns selecting for intermediate fish sizes protect against fishing-induced evolutionary impact. Such exploitation patterns can emerge from dome-shaped gear selectivity, such as gillnets, or spatio-temporal targeting of medium-size fish. In contrast, exploitation patterns selecting for large sizes might have stronger evolutionary impacts (Jørgensen et al. 2009). Cod, haddock and whiting are mainly targeted by mixed demersal fisheries using both trawls and gillnets (ICES 2009), and there is no major difference in selectivity pattern experienced by these 3 species. Norway pout is targeted by industrial trawlers for reduction purposes (fish meal and fish oil), but the state of this stock is not much affected by presently rather low fishing mortality levels. In other words, the temporal steadiness in Norway pout maturity could be a joint result of both weak fishing pressure from 1985 and weak intrinsic sensitivity to evolutionary changes. Therefore, even though our results corroborate theoretical expectations regarding sensitivity of maturation evolutionary response, a meta-analysis on more than 4 stocks would be necessary to significantly discriminate between sensitivity due to life-history strategy and exploitation regime.

Data archive. Data used for this study are held by the International Council for the Exploration of the Sea and available at https://datras.ices.dk/Data_products/Download/ Download_Data_public.aspx.

Acknowledgements. This study was carried out with financial support from the European Commission, as part of the Specific Targeted Research Project on 'Fisheries-induced evolution' (FinE, contract number SSP-2006-044276) under the Scientific Support to Policies cross-cutting activities of the European Community's Sixth Framework Programme. It does not necessarily reflect the views of the European Commission and does not anticipate the Commission's future policy in this area. We thank ICES and the member states that contribute to the IBTS survey for permission to use the data, all members of the FishAce and FinE networks for useful discussions and 6 anonymous referees for relevant comments on a previous version of the paper.

\section{LITERATURE CITED}

Audzijonyte A, Kuparinen A, Fulton EA (2013) How fast is fisheries-induced evolution? Quantitative analysis of modelling and empirical studies. Evol Appl 6:585-595

Barot S, Heino M, O'Brien L, Dieckmann U (2004) Estimating reaction norms for age and size at maturation when age at first reproduction is unknown. Evol Ecol Res 6: 659-678

Baulier L, Heino M (2008) Norwegian spring-spawning herring as the test case of piecewise linear regression method for detecting maturation from growth patterns. J Fish Biol 73:2452-2467

> Berkeley SA, Chapman C, Sogard SM (2004) Maternal age as a determinant of larval growth and survival in a marine fish, Sebastes melanops. Ecology 85:1258-1264

Bernardo J (1993) Determinants of maturation in animals. Trends Ecol Evol 8:166-173

Charlesworth B (1994) Evolution in age-structured populations, 2nd edn. Cambridge University Press, Cambridge

$>$ Charrier G, Coombs SH, McQuinn IH, Laroche J (2007) Genetic structure of whiting Merlangius merlangus in the northeast Atlantic and adjacent waters. Mar Ecol Prog Ser 330:201-211

Coxe KL (1986) Principal components regression analysis. In: Johnson NL, Kotz S (eds) Encyclopedia of statistical sciences, . Wiley, New York, NY, p 181-186

> Devine JA, Heino M (2011) Investigating the drivers of maturation dynamics in Barents Sea haddock (Melanogrammus aeglefinus). Fish Res 110:441-449

> Dhillon RS, Fox MG (2004) Growth-independent effects of temperature on age and size at maturity in Japanese medaka (Oryzias latipes). Copeia 2004:37-45

$>$ Dieckmann U, Heino M (2007) Probabilistic maturation reaction norms: their history, strengths, and limitations. Mar Ecol Prog Ser 335:253-269

Enberg K, Jørgensen C, Dunlop ES, Heino M, Dieckmann U (2009) Implications of fisheries-induced evolution for stock rebuilding and recovery. Evol Appl 2:394-414

Engelhard GH, Dieckmann U, Godø OR (2003) Age at maturation predicted from routine scale measurements in Norwegian spring-spawning herring (Clupea harengus) using discriminant and neural network analyses. ICES J Mar Sci 60:304-313

Ernande B, Dieckmann U, Heino M (2004) Adaptive changes in harvested populations: plasticity and evolution of age and size at maturation. Proc R Soc Lond B Biol Sci 271:415-423

Fekedulegn BD, Colbert JJ, Hicks RRJ, Schuckers ME (2002) Coping with multicollinearity: an example on application of principal components regression in dendroecology. Res Pap NE-721.USDA Forest Service, Northeastern Research Station, Newtown Square, PA

Gårdmark A, Dieckmann U (2006) Disparate maturation adaptations to size-dependent mortality. Proc R Soc Lond B Biol Sci 273:2185-2192 
Grift RE, Rijnsdorp AD, Barot S, Heino M, Dieckmann U (2003) Fisheries-induced trends in reaction norms for maturation in North Sea plaice. Mar Ecol Prog Ser 257: $247-257$

Grift RE, Heino M, Rijnsdorp AD, Kraak SBM, Dieckmann U (2007) Three-dimensional maturation reaction norms for North Sea plaice. Mar Ecol Prog Ser 334:213-224

> Heino M (1998) Management of evolving fish stocks. Can J Fish Aquat Sci 55:1971-1982

Heino M, Dieckmann U (2008) Detecting fisheries-induced life-history evolution: an overview of the reaction-norm approach. Bull Mar Sci 83:69-93

Heino M, Godø OR (2002) Fisheries-induced selection pressures in the context of sustainable fisheries. Bull Mar Sci 70:639-656

Heino M, Dieckmann U, Godø OR (2002a) Measuring probabilistic reaction norms for age and size at maturation. Evolution 56:669-678

Heino M, Dieckmann U, Godø OR (2002b) Reaction norm analysis of fisheries-induced adaptive change and the case of the Northeast Arctic cod. ICES CM 2002/Y:14 (Abstract). ICES, Copenhagen

Hislop JRG (1984) A comparison of the reproductive tactics and strategies of cod, haddock, whiting and Norway pout in the North Sea. In: Potts GW, Wooton RJ (eds) Fish reproduction: strategies and tactics. Academic Press, London, p 311-328

Hislop JRG (coord) (1997) Database report of the stomach sampling project 1991. ICES Coop Res Rep 219. ICES, Copenhagen

Hobbs JPA, Munday PL, Jones GP (2004) Social induction of maturation and sex determination in a coral reef fish. Proc R Soc Lond B Biol Sci 271:2109-2114

Holm S (1979) A simple sequentially rejective multiple test procedure. Scand J Stat 6:65-70

> Hutchings JA (2005) Life history consequences of overexploitation to population recovery in Northwest Atlantic cod (Gadus morhua). Can J Fish Aquat Sci 62:824-832

Hutchings JA, Fraser DJ (2008) The nature of fisheries- and farming-induced evolution. Mol Ecol 17:294-313

Hutchings JA, Bishop TD, McGregor-Shaw CR (1999) Spawning behaviour of Atlantic cod, Gadus morhua: evidence of mate competition and mate choice in a broadcast spawner. Can J Fish Aquat Sci 56:97-104

Hutchinson WF, Carvalho GR, Rogers SI (2001) Marked genetic structuring in localised spawning populations of cod Gadus morhua in the North Sea and adjoining waters, as revealed by microsatellites. Mar Ecol Prog Ser 223:251-260

ICES (International Council for the Exploration of the Sea) (2009) Report of the Working Group on the assessment of demersal stocks in the North Sea and Skagerrak - combined spring and autumn (WGNSSK). ICES, Copenhagen. www.ices.dk/sites/pub/Publication\%20Reports/ Expert\%20Group\%20Report/acom/2009/WGNSSK/ WGNSSK09.pdf

ICES (2010) Manual for the International Bottom Trawl Surveys. Series of ICES Survey Protocols. SISP 1 - IBTS VIII. ICES, Copenhagen

ICES (2012) Report of the Working Group on the assessment of demersal stocks in the North Sea and Skagerrakcombined spring and autumn (WGNSSK). ICES, Copenhagen. www.ices.dk/sites/pub/Publication Reports/ Expert Group Report/acom/2012/WGNSSK/WGNSSK 2012.pdf
Jakobsen T, Ajiad A (1999) Management implications of sexual differences in maturation and spawning mortality of Northeast Arctic cod. J Northwest Atl Fish Sci 25: $125-131$

> Jørgensen T (1990) Long-term changes in age at sexual maturity of Northeast Arctic cod (Gadus morhua L.). ICES J Mar Sci 46:235-248

Jørgensen C, Enberg K, Dunlop ES, Arlinghaus R and others (2007) Managing evolving fish stocks. Science 318: 1247-1248

Jørgensen C, Ernande B, Fiksen Ø (2009) Size-selective fishing gear and life history evolution in the Northeast Arctic cod. Evol Appl 2:356-370

Kinnison MT, Quinn TP, Unwin MJ (2011) Correlated contemporary evolution of life history traits in New Zealand Chinook salmon, Oncorhynchus tshawytscha. Heredity 106:448-459

> Kjesbu OS, Witthames PR (2007) Evolutionary pressure on reproductive strategies in flatfish and groundfish: relevant concepts and methodological advancements. J Sea Res 58:23-34

Kozłowski J (1992) Optimal allocation of resources to growth and reproduction: implications for age and size at maturity. Trends Ecol Evol 7:15-19

Kozłowski J, Wiegert RG (1986) Optimal allocation of energy to growth and reproduction. Theor Popul Biol 29: $16-37$

Kozłowski J, Wiegert RG (1987) Optimal age and size at maturity in annuals and perennials with determinate growth. Evol Ecol 1:231-244

Kraak SBM (2007) Does the probabilistic maturation reaction norm approach disentangle phenotypic plasticity from genetic change? Mar Ecol Prog Ser 335:295-300

Kuparinen A, Merilä J (2007) Detecting and managing fisheries-induced evolution. Trends Ecol Evol 22:652-659

Lambert G, Nielsen JR, Larsen LI, Sparholt H (2009) Maturity and growth population dynamics of Norway pout (Trisopterus esmarkii) in the North Sea, Skagerrak, and Kattegat. ICES J Mar Sci 66:1899-1914

$>$ Law R (2000) Fishing, selection, and phenotypic evolution. ICES J Mar Sci 57:659-668

> Law R (2007) Fisheries-induced evolution: present status and future directions. Mar Ecol Prog Ser 335:271-277

Law R, Grey D (1989) Evolution of yields from populations with age-specific cropping. Evol Ecol 3:343-359

Manly BF (1997) Randomization, bootstrap, and Monte Carlo methods in biology, 2nd edn. Chapman \& Hall, London

Marshall CT, McAdam BJ (2007) Integrated perspectives on genetic and environmental effects on maturation can reduce potential for errors of inference. Mar Ecol Prog Ser 335:301-310

> Marteinsdottir G, Begg GA (2002) Essential relationships incorporating the influence of age, size and condition on variables required for estimation of reproductive potential in Atlantic cod Gadus morhua. Mar Ecol Prog Ser 235:235-256

Marty L, Dieckmann U, Rochet MJ, Ernande B (2011) Impact of environmental covariation in growth and mortality on evolving maturation reaction norms. Am Nat 177: E98-E118

Mollet FM, Kraak SBM, Rijnsdorp AD (2007) Fisheriesinduced evolutionary changes in maturation reaction norms in North Sea sole Solea solea. Mar Ecol Prog Ser 351:189-199 
Mollet FM, Ernande B, Brunel T, Rijnsdorp AD (2010) Multiple growth-correlated life history traits estimated simultaneously in individuals. Oikos 119:10-26

Morita K, Fukuwaka M (2006) Does size matter most? The effect of growth history on probabilistic reaction norm for salmon maturation. Evolution 60:1516-1521

Morita K, Fukuwaka M (2007) Why age and size at maturity have changed in Pacific salmon. Mar Ecol Prog Ser 335: 289-294

Morita K, Tsuboi J, Nagasawa T (2009) Plasticity in probabilistic reaction norms for maturation in a salmonid fish. Biol Lett 5:628-631

Neuheimer AB, Grønkjær P (2012) Climate effects on sizeat-age: growth in warming waters compensates for earlier maturity in an exploited marine fish. Glob Change Biol 18:1812-1822

> Neuheimer AB, Taggart CT (2010) Can changes in lengthat-age and maturation timing in Scotian Shelf haddock (Melanogrammus aeglefinus) be explained by fishing? Can J Fish Aquat Sci 67:854-865

Nielsen EE, Wright PJ, Hemmer-Hansen J, Poulsen NA, Monro Gibb I, Meldrup D (2009) Microgeographical population structure of cod Gadus morhua in the North Sea and west of Scotland: the role of sampling loci and individuals. Mar Ecol Prog Ser 376:213-225

> Olsen EM, Heino M, Lilly GR, Morgan MJ, Brattey J, Ernande B, Dieckmann U (2004) Maturation trends indicative of rapid evolution preceded the collapse of northern cod. Nature 428:932-935

Olsen EM, Lilly GR, Heino M, Morgan JB, Brattey J, Dieckmann U (2005) Assessing changes in age and size at maturation in collapsing populations of Atlantic cod (Gadus morhua). Can J Fish Aquat Sci 62:811-823

Pardoe H, Vainikka A, Thórdarson G, Marteinsdóttir G, Heino M (2009) Temporal trends in probabilistic maturation reaction norms and growth of Atlantic cod (Gadus morhua) on the Icelandic shelf. Can J Fish Aquat Sci 66: 1719-1733

R Development Core Team (2013) R: a language and environment for statistical computing. R Foundation for Statistical Computing, Vienna

Reznick DN (1993) Norms of reaction in fishes. In: Stokes TK, McGlade JM, Law R (eds) The exploitation of evolving resources. Springer-Verlag, Berlin, p 72-90

Rochet MJ (2000a) May life history traits be used as indices of population viability? J Sea Res 44:145-157

Rochet MJ (2000b) Spatial and temporal patterns in age and size at maturity and spawning stock biomass of North Sea gadoids. ICES CM 2000/ N:26:13 (Abstract). ICES, Copenhagen

Rowell CA (1993) The effects of fishing on the timing of

Editorial responsibility: Konstantinos Stergiou,

Thessaloniki, Greece maturity in North Sea cod (Gadus morhua L.). In: Stokes TK, McGlade JM, Law R (eds) The exploitation of evolving resources. Springer-Verlag, Berlin, p 44-61

Sharpe DMT, Hendry AP (2009) Life history change in commercially exploited fish stocks: an analysis of trends across studies. Evol Appl 2:260-275

Siems DP, Sikes RS (1998) Tradeoffs between growth and reproduction in response to temporal variation in food supply. Environ Biol Fishes 53:319-329

Sohn JJ (1977) Socially induced inhibition of genetically determined maturation in the platyfish, Xiphophorus maculatus. Science 195:199-201

Sparholt H, Larsen LI, Nielsen JR (2002) Verification of multispecies interactions in the North Sea by trawl survey data on Norway pout (Trisopterus esmarkii). ICES J Mar Sci 59:1270-1275

Stearns SC (1992) The evolution of life histories. Oxford University Press, Oxford

Stearns SC, Crandall RE (1984) Plasticity for age and size at sexual maturity: a life-history response to unavoidable stress. In: Potts G, Wootton RJ (eds) Fish reproduction. Academic Press, London, p 13-33

> Stearns SC, Koella JC (1986) The evolution of phenotypic plasticity in life-history traits: predictions of reaction norms for age and size at maturity. Evolution 40:893-913

Trippel EA (1995) Age at maturity as a stress indicator in fisheries. Bioscience 45:759-771

Uusi-Heikkilä S, Kuparinen A, Wolter C, Meinelt T, O'Toole AC, Arlinghaus R (2011) Experimental assessment of the probabilistic maturation reaction norm: condition matters. Proc R Soc Lond B Biol Sci 278:709-717

- Vainikka A, Gardmark A, Bland B, Hjelm J (2009) Two- and three-dimensional maturation reaction norms for the eastern Baltic cod, Gadus morhua. ICES J Mar Sci 66: 248-257

- Weatherley AH (1990) Approaches to understanding fish growth. Trans Am Fish Soc 119:662-672

> Wright PJ, Neat FC, Gibb FM, Gibb IM, Thordarson H (2006) Evidence for metapopulation structuring in cod from the west of Scotland and North Sea. J Fish Biol 69: 181-199

Wright PJ, Gibb FM, Gibb IM, Millar CP (2011a) Reproductive investment in the North Sea haddock: temporal and spatial variation. Mar Ecol Prog Ser 432:149-160

> Wright PJ, Millar CP, Gibb FM (2011b) Intrastock differences in maturation schedules of Atlantic cod, Gadus morhua. ICES J Mar Sci 68:1918-1927

> Yoneda M, Wright PJ (2004) Temporal and spatial variation in reproductive investment of Atlantic cod Gadus morhua in the northern North Sea and Scottish west coast. Mar Ecol Prog Ser 276:237-248

Submitted: May 24, 2013; Accepted: October 2, 2013 Proofs received from author(s): January 13, 2014 